\title{
Ice nucleation efficiency of AgI: review and new insights
}

\author{
Claudia Marcolli $^{1,2}$, Baban Nagare ${ }^{1}$, André Welti ${ }^{1,3}$, and Ulrike Lohmann ${ }^{1}$ \\ ${ }^{1}$ Institute for Atmospheric and Climate Science, ETH Zurich, Zurich, Switzerland \\ ${ }^{2}$ Marcolli Chemistry and Physics Consulting GmbH, Zurich, Switzerland \\ ${ }^{3}$ Leibniz Institute for Tropospheric Research (TROPOS), Leipzig, Germany
}

Correspondence to: Claudia Marcolli (claudia.marcolli@env.ethz.ch)

Received: 25 January 2016 - Published in Atmos. Chem. Phys. Discuss.: 1 February 2016

Revised: 24 May 2016 - Accepted: 8 June 2016 - Published: 19 July 2016

\begin{abstract}
AgI is one of the best-investigated ice-nucleating substances. It has relevance for the atmosphere since it is used for glaciogenic cloud seeding. Theoretical and experimental studies over the last 60 years provide a complex picture of silver iodide as an ice-nucleating agent with conflicting and inconsistent results. This review compares experimental ice nucleation studies in order to analyze the factors that influence the ice nucleation ability of AgI. The following picture emerges from this analysis: the ice nucleation ability of $\mathrm{AgI}$ seems to be enhanced when the AgI particle is on the surface of a droplet, which is indeed the position that a particle takes when it can freely move in a droplet. The ice nucleation by particles with surfaces exposed to air depends on water adsorption. AgI surfaces seem to be most efficient at nucleating ice when they are exposed to relative humidity at or even above water saturation. For AgI particles that are completely immersed in water, the freezing temperature increases with increasing AgI surface area. Higher threshold freezing temperatures seem to correlate with improved lattice matches as can be seen for $\mathrm{AgI}-\mathrm{AgCl}$ solid solutions and $3 \mathrm{AgI} \cdot \mathrm{NH}_{4} \mathrm{I} \cdot 6 \mathrm{H}_{2} \mathrm{O}$, which have slightly better lattice matches with ice than $\mathrm{AgI}$ and also higher threshold freezing temperatures. However, the effect of a good lattice match is annihilated when the surfaces have charges. Also, the ice nucleation ability seems to decrease during dissolution of AgI particles. This introduces an additional history and time dependence for ice nucleation in cloud chambers with short residence times.
\end{abstract}

\section{Introduction}

Cloud glaciation is an important process that influences cloud optical properties, cloud lifetime and precipitation. While cloud droplets freeze homogeneously below about $237 \mathrm{~K}$, ice-nucleating particles are needed to freeze droplets at higher temperatures. When Vonnegut (1947) observed that a piece of silver iodide is able to freeze liquid water below $269.65 \mathrm{~K}$, he attributed this high ice nucleation ability to the close fit between the crystal lattices of ice and AgI. However, the importance of lattice match was questioned thereupon because ice seems to nucleate preferentially at steps on the silver iodide surface and the hexagonal pattern only appears when the growing ice crystal has gained some size (Zettlemoyer et al., 1961). Crystals such as cadmium sulfide (CdS), quartz, indium antimonide (InSb) and barium fluoride $(\mathrm{BaF} 2)$ are ineffective as ice nuclei despite similar lattice spacing to ice (Edwards and Evans, 1962; Sadtchenko et al., 2002; Conrad et al., 2005). Moreover, examples of organic ice-nucleating substances like crystalline steroids nucleate ice almost as effectively as AgI, but their crystal lattices exhibit no obvious relationship to the cell dimensions of ice (Head, 1961). The importance of lattice match was further questioned when it was detected that the silver iodide surface is mainly hydrophobic with isolated hydrophilic patches. It was then conjectured that these hydrophilic sites, which may be chemical defects, steps in the crystal lattice or hygroscopic contaminants (Corrin and Nelson, 1968; Zettlemoyer et al., 1963), are indeed the locations where ice nucleation occurs rather than perfect faces of AgI crystals. On the other hand, the structures of some of the most efficient ice-nucleating substances closely match the ice lattice. Water freezes at temperatures as high as $272 \mathrm{~K}$ when covered 
by a monolayer of long-chain alcohols forming 2-D crystals with close lattice matches to ice (Popovitz-Biro et al., 1994; Majewski et al., 1995; Cantrell and Robinson, 2006; Zobrist et al., 2007; Knopf and Forrester, 2011). Ice active proteins expressed by the bacteria Pseudomonas syringae ( $P$. Syringae) and Erwinia herbicola, which are ice active up to $271 \mathrm{~K}$, possess sites with a close fit to the ice lattice (Kajava and Lindow, 1993; Yankofsky et al., 1981; Govindarajan and Lindow, 1988; Budke and Koop, 2015). Therefore, a good ice lattice match with ice seems to be one of the properties that promotes ice nucleation, but it is certainly not the only one. Other properties may be a low surface charge and large polarizability of the ice-nucleating surface. Further factors are the orientation of hydrogen bonds and van der Waals interactions between the ice-nucleating structure and water molecules (Sadtchenko et al., 2002; Zielke et al., 2015). Fletcher (1959) pointed out that the molecular alignment of water molecules directed by hydrogen bonds must be favorable for the growth of further ice layers; otherwise, epitaxial ice growth is inhibited.

AgI has become one of the best-investigated icenucleating agents. It is of relevance for the atmosphere because of its use for glaciogenic seeding of clouds to increase precipitation and to prevent hail (Silverman, 2001). Theoretical and experimental studies over the last 60 years provide a complex picture of silver iodide as an ice-nucleating agent with conflicting and inconsistent results. We have performed experiments to compare contact and immersion freezing yielding results contrasting with earlier studies. These new experiments are described here and in a companion paper (Nagare et al., 2016). The aim of this review is to compare experimental ice nucleation studies with AgI and to see whether seemingly conflicting results can be brought into agreement when the nucleation conditions are considered in more detail. Such an analysis should also allow us to identify factors that influence the ice nucleation efficiency of silver iodide. Moreover, this survey may show exemplarily what factors determine the efficiency of ice-nucleating agents in general. This is one of three papers that present and analyze contact freezing experiments with AgI. In Nagare et al. (2015) collision efficiencies based on contact freezing experiments with AgI are determined and compared with theoretical formulations. In a companion paper (Nagare et al., 2016), contact freezing experiments are compared with immersion freezing experiments conducted with AgI, kaolinite and Arizona Test Dust (ATD) as ice-nucleating particles.

This review is structured as follows: in Sect. 2 new experimental results of immersion freezing with AgI are presented. Section 3 explains the different modes of ice nucleation and gives a literature review of ice nucleation studies performed with silver iodide ordered according to experimental techniques. The text is complemented by four tables, which summarize details of the experimental studies performed in immersion mode (Table 1), contact mode (Table 2), condensation mode (Table 3) and deposition mode (Table 4). Section 4 discusses the experimental findings with respect to factors that are supposed to influence the ice nucleation ability of AgI. The main text ends with conclusions summarizing the most important factors influencing the ice-nucleating ability of AgI and is supplemented by appendices, which summarize the physical properties of AgI relevant for ice nucleation.

\section{IMCA-ZINC experiments with AgI}

Immersion freezing experiments were carried out with the Immersion Mode Cooling chAmber-Zurich Ice Nucleation Chamber (IMCA-ZINC) setup, which combines the cloud droplet activation chamber IMCA with the ice nucleation chamber ZINC (Lüönd et al., 2010). The aerosol particles are activated as CCN in the IMCA part at $\mathrm{RH}>120 \%$ and $T>300 \mathrm{~K}$. The activated droplets grow to $18-20 \mu \mathrm{m}$ in diameter within about $10 \mathrm{~s}$ when they pass through the IMCA chamber. The droplets cool down on their way to the ZINC chamber, where they reach the target temperatures. The residence time in the ZINC chamber, which is kept at water saturation, can be varied between 1 and $21 \mathrm{~s}$ by changing the position of the IODE (Ice Optical DEpolarization) detector (Nicolet et al., 2010) and the additional sheath air in the ZINC chamber (see Welti et al., 2012).

A suspension of AgI particles was prepared by mixing 0.1 M KI and $\mathrm{AgNO}_{3}$ solutions in Milli-Q water (18.2 M $\Omega$ ). Particles were generated by atomizing the produced suspension and subsequently dried (as described in Nagare et al., 2015). Particle characterization is given in Appendix A. Xray diffractograms showed that a mixture of the $\beta$ and $\gamma$ forms precipitated, which needed days to transform into the $\beta$ form. The size distribution of the AgI particles peaks at diameters of about $70 \mathrm{~nm}$ as shown in Fig. A1. The concentration of particles present in the Milli-Q water, by contrast, peaks at $35 \mathrm{~nm}$ and vanishes at diameters $>100 \mathrm{~nm}$. It dominates over the AgI particle concentration at diameters $<30 \mathrm{~nm}$. Figure A2 shows STEM (scanning transmission electron microscopy) images of representative AgI particles. The precipitated particles are of irregular shapes and consist of conglomerates of $\mathrm{AgI}$ and $\mathrm{KNO}_{3}$.

In one set of experiments, particle size was varied between 20 and $400 \mathrm{~nm}$ for a droplet residence time of $10 \mathrm{~s}$. These experiments are shown in panel (a) of Fig. 1. For particles with diameters of $40-400 \mathrm{~nm}$, median freezing was observed at ca. $264 \mathrm{~K}$ almost independent of particle size. For $30 \mathrm{~nm}$ particles, the median freezing temperature decreased to $259 \mathrm{~K}$ and the heterogeneously frozen fraction leveled off at ca. 0.9, indicating that $10 \%$ of the particles did not induce ice nucleation. For particle diameters of $20 \mathrm{~nm}$, most droplets froze homogeneously. Langer et al. (1978) showed that $20 \mathrm{~nm}$ particles produced by heating AgI induced freezing at $253 \mathrm{~K}$. Therefore, the small size alone cannot be the reason why ice nucleation decreased drastically for particles $<40 \mathrm{~nm}$. Indeed, comparing the size distribution obtained by atomizing 

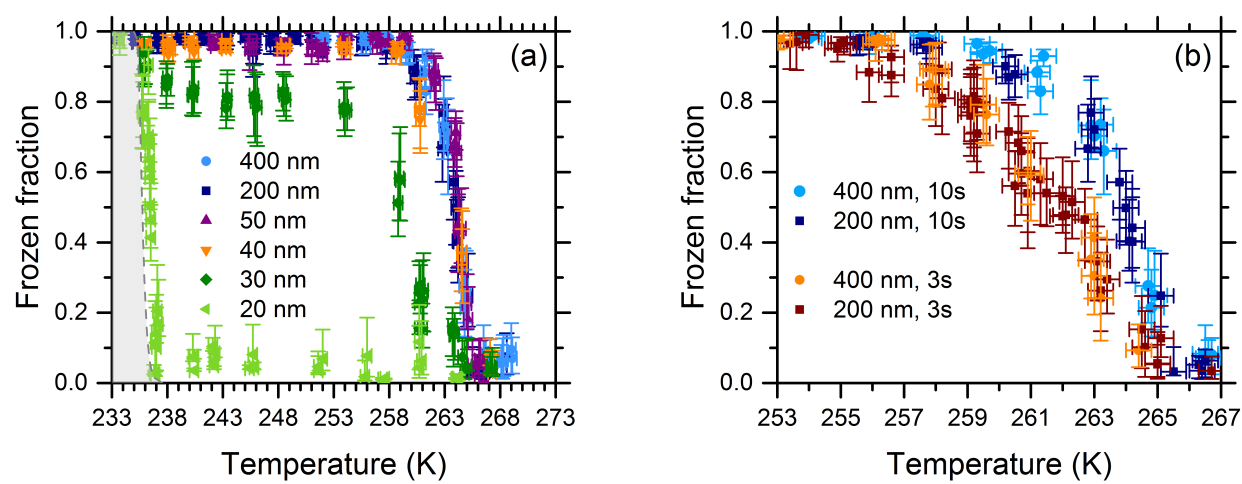

Figure 1. Immersion freezing experiments performed with the IMCA-ZINC setup. Panel (a): particle diameter dependence of frozen fraction. The gray shaded area indicates homogeneous freezing. Panel (b): time dependence. Note that the scales of the $x$ axes in panels (a) and (b) are different. Error bars represent the uncertainty in the frozen fraction due to the classification (liquid or ice) uncertainty of the IODE detector (Lüönd et al., 2010).

the $\mathrm{AgI}$ suspension with the one obtained by atomizing pure Milli-Q water (Fig. A1) reveals that $30 \mathrm{~nm}$ diameter particles produced by the atomization of the AgI suspension contained a minor fraction of particles originating from the Milli-Q water, and the $20 \mathrm{~nm}$ size fraction is even dominated by these particles.

For 200 and $400 \mathrm{~nm} \mathrm{AgI} \mathrm{particles,} \mathrm{experiments} \mathrm{with} \mathrm{a} 3 \mathrm{~s}$ residence time in the ZINC chamber were also carried out. This shorter residence time decreased the median freezing temperature by $1-2 \mathrm{~K}$ as shown in panel (b) of Fig. 1.

\section{Literature review}

\subsection{Modes of heterogeneous ice nucleation}

Heterogeneous ice nucleation may take place with the help of ice-nucleating substances between 237 and $273 \mathrm{~K}$ in the mixed-phase cloud regime. In this regime, three pathways of ice nucleation are differentiated, namely, immersion freezing, condensation freezing and contact freezing. Probably the most important process is immersion freezing, where an icenucleating particle located within the body of a supercooled liquid particle (cloud droplet or solution particle) initiates freezing (Vali et al., 2015). Similar to this mode, condensation freezing denotes ice nucleation that is initiated concurrently with the initial formation of liquid water on a cloud condensation nucleus $(\mathrm{CCN})$ at temperatures below the melting point of ice (Vali et al., 2015). These two modes of freezing are usually discriminated although it is not clear whether they do indeed occur at different rates.

Originally, contact freezing referred to freezing initiated by the collision of an aerosol particle with a supercooled droplet (Ladino Moreno et al., 2013). This view of collisional contact freezing has been complemented by Durant and Shaw (2005), who found higher ice nucleation temperatures compared with the immersion mode when an ice nu- cleus was in contact with the water-air interface of a droplet, from either the inside or the outside (Durant and Shaw, 2005; Gurganus et al., 2014; Fornea et al., 2009; Murray et al., 2012; Shaw et al., 2005). We refer to a contact nucleation process as adhesion freezing when the position of the particle on the water surface enhances the ice nucleation efficiency compared with immersion freezing and discriminate it from collisional contact freezing, which assumes an enhancement due to the collision of the particle with the droplet (Nagare et al., 2016).

Deposition nucleation takes place when ice nucleates on a substrate directly from the gas phase with no liquid water involved. This concept was recently challenged by Marcolli (2014), who hypothesized that in conditions below water saturation, liquid water condenses in pores because of the inverse Kelvin effect (Sjogren et al., 2007), and that in most cases of ice nucleation below water saturation, pore water is involved.

\subsection{Ice nucleation experiments}

Tables 1-4 compile setups and procedures of immersion, contact, condensation and deposition nucleation experiments performed with silver iodide. The information given by the different studies is very diverse, which often limits direct comparisons. Some studies report the onset of freezing, which is usually significantly higher than a mean or median freezing temperature. The number or concentration of particles is often missing, preventing the evaluation of surface area present in a droplet. Figure 2 shows median freezing temperatures $T_{\mathrm{M}}$ for frozen fractions ranging from 0.2 to 0.8 as a function of surface area for the studies that provide enough information to determine or to estimate these quantities. The presented data is coded with respect to freezing mode (open symbols: contact freezing; filled symbols: immersion freezing) and studies (different colors and symbols). As a general trend, Fig. 2 shows an increase in $T_{\mathrm{M}}$ with in- 


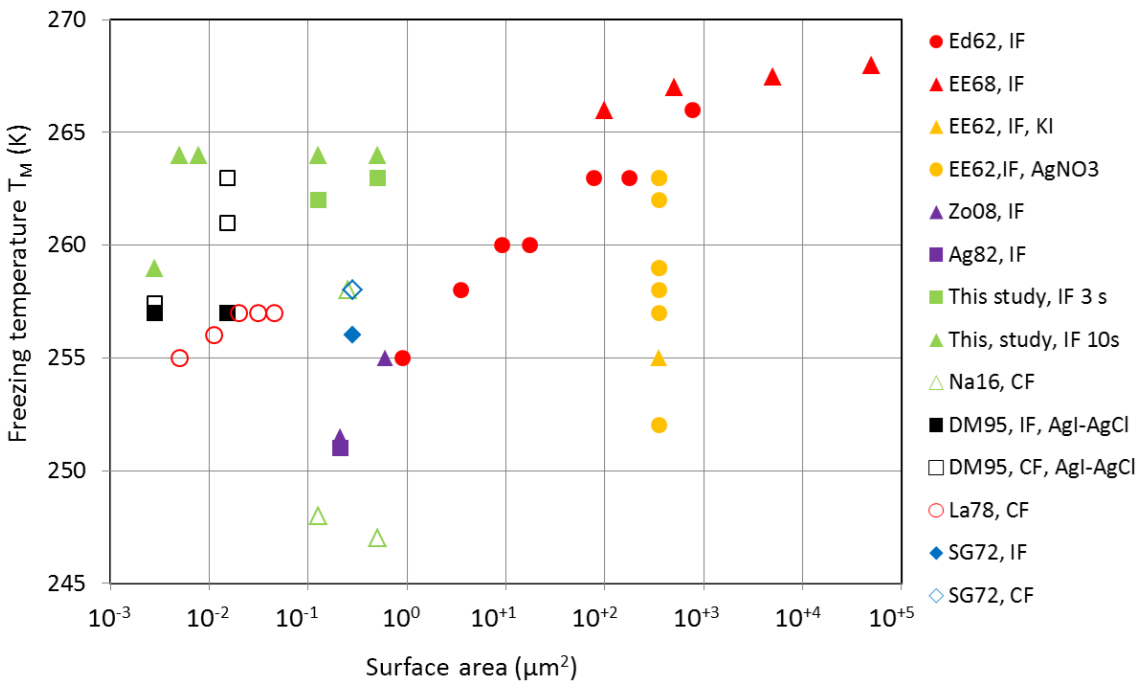

Figure 2. Median freezing temperatures $T_{\mathrm{M}}$ as a function of particle surface area per droplet for immersion freezing (IF, filled symbols) and contact freezing (CF, open symbols). Filled red symbols: droplets on hydrophobic glass slips with previously deposited AgI particles prepared by precipitation in stoichiometric ratio (circles: Edwards et al., 1962, Ed62; triangles: Edwards and Evans, 1968, EE68). Filled orange symbols: droplets on hydrophobic glass slips with previously deposited AgI particles prepared by precipitation in nonstoichiometric ratio (Edwards and Evans, 1962, EE62; circles: excess of $\mathrm{AgNO}_{3}$; triangles: excess of KI; note that circles and triangles overlap). Filled purple symbols: emulsion of AgI containing water droplets prepared by in situ precipitation in stoichiometric ratio (triangles: Zobrist et al., 2008, Zo08; square: Aguerd et al., 1982, Ag82). Filled green symbols: freely falling water droplets with immersed AgI particle (squares: this study, $3 \mathrm{~s}$ residence time; triangles: this study, $10 \mathrm{~s}$ residence time). Open green triangles: water droplets freely falling through chamber with AgI aerosol (Nagare et al., 2016, Na16). Filled black squares: cloud chamber filled with droplets from CCN activation of $\mathrm{AgI}-\mathrm{AgCl}$ particles (DeMott, 1995, DM95). Open black squares: water droplets in cloud chamber with AgI-AgCl aerosol (DeMott, 1995). Open red circles: water droplets in cloud chamber filled with AgI aerosol (Langer, 1978, La78). Blue diamonds: freely falling droplets intercepting AgI aerosol; filled diamond: immersion mode; open diamond: contact mode (Sax and Goldsmith, 1972, SG72).

creasing silver iodide surface area present per droplet. However, there are also many exceptions, showing that surface area is an important factor but not the only one determining nucleation temperature. In the following subsections the experimental studies are presented sorted by experimental techniques.

\subsubsection{Particles and droplets deposited on substrates}

Edwards et al. (1962) investigated ice nucleation in immersion mode by monodisperse AgI particles in a cold stage (see Table 1). They prepared monodisperse AgI suspensions of single crystals with particle diameters of $0.17 \pm 0.02 \mu \mathrm{m}$, $0.75 \pm 0.1 \mu \mathrm{m}$ and $3.5 \pm 0.4 \mu \mathrm{m}$ by slowly precipitating $\mathrm{AgI}$ with seed solutions containing AgI particles of different concentrations, so that crystals grew on the seed particles and no nucleation took place. The larger particles crystallized as hexagonal pyramids; smaller ones were more rounded. The particles were deposited onto hydrophobic glass cover slips, to which they adhered. Droplets of water or aqueous solutions were sprayed on the slips, which were then flooded with paraffin oil to prevent evaporation. The droplets contained $10^{-4} \mathrm{M} \mathrm{AgNO}_{3}$ to offset the natural tendency of silver iodide prepared by this method to enrich iodide ions on the surface. The glass cover slips were cooled at a rate of $2 \mathrm{~K} \mathrm{~min}^{-1}$ in the cold stage, and $T_{50}$, the temperature at which $50 \%$ of the droplets with sizes between 30 and $60 \mu \mathrm{m}$ had frozen, was reported. Generally, all droplets froze within about $4 \mathrm{~K}$. The data from Edwards et al. (1962), given as red filled circles in Fig. 2, show a clear dependence of freezing temperature on surface area. The same experimental procedure was also used by Edwards and Evans (1968). Their AgI crystals had average diameters of $4 \mu \mathrm{m}(2-5 \mu \mathrm{m})$ and a crystal habit of hexagonal plates. Droplets sprayed on cover slips contained between 1 and 1000 particles. The $T_{50}$ values of this study given as red triangles in Fig. 2 are in fair agreement with the previous study by Edwards et al. (1962). Using the same method, Edwards and Evans (1962) investigated the dependence of freezing temperature on excess $\mathrm{Ag}^{+}$and $\mathrm{I}^{-}$ions, which adsorb to the surface of AgI particles and influence their surface charge. To do this, they diluted a saturated AgI solution once with a $0.2 \mathrm{M}$ KI solution containing the seed aerosol (sol A) and once with a $0.2 \mathrm{M} \mathrm{AgNO}_{3}$ solution (sol B) leading to excess $\mathrm{I}^{-}$(orange triangles) and excess $\mathrm{Ag}^{+}$ (orange circles), respectively. It can be seen from Table 1 and Fig. 2 (symbols overlap) that in KI solutions with concentrations $>10^{-5} \mathrm{M}$ and $\mathrm{AgNO}_{3}$ solutions with concentrations $>10^{-3} \mathrm{M}$, the freezing temperatures drop, manifesting 
Table 1. Immersion freezing studies with $\mathrm{AgI}$ or related salts: IN - ice nuclei; $D_{\mathrm{D}}-$ droplet diameter; $C_{\mathrm{p}}-$ particle concentration; $D_{\mathrm{p}}-$ particle diameter; $T_{\mathrm{f}}$ - freezing temperature; $C_{\mathrm{D}}$ - droplet concentration. References: Ed62 - Edwards et al. (1962); EE68 - Edwards and Evans (1968); EE62 - Edwards and Evans (1962); Zo08 - Zobrist et al. (2008); Ag82 - Aguerd et al. (1982); Ho61 - Hoffer (1961); SG72 Sax and Goldsmith (1972); DM95 - DeMott (1995); VB84 - Vonnegut and Baldwin (1984); Pa86 - Palanisamy et al. (1986a); Da75 - Davis et al. (1975); DSC - differential scanning calorimeter.

\begin{tabular}{|c|c|c|c|c|c|c|c|c|}
\hline IN & Preparation & Setup & $D_{\mathrm{D}} \&$ prep & $C_{\mathrm{p}}$ & $D_{\mathrm{p}}$ & Activation & $T_{\mathrm{f}}$ & Refs \\
\hline $\mathrm{AgI}$ & $\begin{array}{l}\text { Precipitation from } \\
\text { AgI-saturated } \\
\text { solution on seeds, } \\
\text { deposited on cover } \\
\text { slips }\end{array}$ & $\begin{array}{l}\text { Cold stage; } \\
\text { droplets on } \\
\text { hydrophobic glass } \\
\text { cover slips }\end{array}$ & $\begin{array}{l}30-60 \mu \mathrm{m} \text {, } \\
\text { av. } 50 \mu \mathrm{m} \\
\text { sprayed from atom- } \\
\text { izer on cover slips }\end{array}$ & $\begin{array}{l}\text { 10/drop } \\
100 / \text { drop } \\
2 / \text { drop } \\
\text { 10/drop } \\
\text { 100/drop } \\
2 / \text { drop } \\
20 / \text { drop }\end{array}$ & $\begin{array}{l}170 \mathrm{~nm} \\
170 \mathrm{~nm} \\
750 \mathrm{~nm} \\
750 \mathrm{~nm} \\
750 \mathrm{~nm} \\
3.5 \mu \mathrm{m} \\
3.5 \mu \mathrm{m}\end{array}$ & $\begin{array}{l}50 \% \\
50 \% \\
50 \% \\
50 \% \\
50 \% \\
50 \% \\
50 \%\end{array}$ & $\begin{array}{l}255 \mathrm{~K} \\
260 \mathrm{~K} \\
258 \mathrm{~K} \\
260 \mathrm{~K} \\
263 \mathrm{~K} \\
263 \mathrm{~K} \\
266 \mathrm{~K}\end{array}$ & Ed62 \\
\hline $\mathrm{AgI}$ & $\begin{array}{l}\text { Precipitation from } \\
\text { AgI-saturated } \\
\text { solution on seeds, } \\
\text { deposited on cover } \\
\text { slips }\end{array}$ & $\begin{array}{l}\text { Cold stage; } \\
\text { droplets on } \\
\text { hydrophobic glass } \\
\text { cover slips }\end{array}$ & $\begin{array}{l}\sim 100 \mu \mathrm{m} \\
\text { sprayed from atom- } \\
\text { izer on cover slips }\end{array}$ & $\begin{array}{l}\text { 1000/drop } \\
100 / \text { drop } \\
10 / \text { drop } \\
2 / \text { drop }\end{array}$ & $\begin{array}{l}4 \mu \mathrm{m} \\
4 \mu \mathrm{m} \\
4 \mu \mathrm{m} \\
4 \mu \mathrm{m}\end{array}$ & $\begin{array}{l}50 \% \\
50 \% \\
50 \% \\
50 \%\end{array}$ & $\begin{array}{l}268 \mathrm{~K} \\
267.5 \mathrm{~K} \\
267 \mathrm{~K} \\
266 \mathrm{~K}\end{array}$ & EE68 \\
\hline $\mathrm{AgI}$ & $\begin{array}{l}\text { Precipitation from } \\
\text { AgI-saturated } \\
\text { solution on seeds, } \\
\text { deposited on cover } \\
\text { slips }\end{array}$ & $\begin{array}{l}\text { Cold stage; } \\
\text { droplets on } \\
\text { hydrophobic glass } \\
\text { cover slips, } \\
\text { sol A: excess } \mathrm{Ag}^{+}\end{array}$ & $\begin{array}{l}30-60 \mu \mathrm{m}, \\
\text { av. } 50 \mu \mathrm{m} \\
\text { sprayed from atom- } \\
\text { izer on cover slips } \\
(\sim 40) \text { covered with } \\
\text { paraffin oil }\end{array}$ & $\begin{array}{l}\text { 200/drop } \\
10^{-2} \mathrm{M} \mathrm{AgNO}_{3} \\
10^{-3} \mathrm{M} \mathrm{AgNO}_{3} \\
10^{-4} \mathrm{M} \mathrm{AgNO}_{3} \\
10^{-5} \mathrm{M} \mathrm{AgNO}_{3} \\
10^{-6} \mathrm{M} \mathrm{AgNO}_{3} \\
\mathrm{H}_{2} \mathrm{O} \\
10^{-3} \mathrm{M} \mathrm{KI} \\
10^{-4} \mathrm{M} \mathrm{KI} \\
10^{-5} \mathrm{M} \mathrm{KI}\end{array}$ & $\begin{array}{l}750 \mathrm{~nm} \\
750 \mathrm{~nm} \\
750 \mathrm{~nm} \\
750 \mathrm{~nm} \\
750 \mathrm{~nm} \\
750 \mathrm{~nm} \\
750 \mathrm{~nm} \\
750 \mathrm{~nm} \\
750 \mathrm{~nm}\end{array}$ & $\begin{array}{l}50 \% \\
50 \% \\
50 \% \\
50 \% \\
50 \% \\
50 \% \\
50 \% \\
50 \% \\
50 \%\end{array}$ & $\begin{array}{l}257 \mathrm{~K} \\
259 \mathrm{~K} \\
262 \mathrm{~K} \\
263 \mathrm{~K} \\
259 \mathrm{~K} \\
255 \mathrm{~K} \\
255 \mathrm{~K} \\
255 \mathrm{~K} \\
255 \mathrm{~K}\end{array}$ & EE62 \\
\hline $\mathrm{AgI}$ & $\begin{array}{l}\text { Precipitation from } \\
\text { AgI-saturated } \\
\text { solution on seeds, } \\
\text { deposited on cover } \\
\text { slips }\end{array}$ & $\begin{array}{l}\text { Cold stage; } \\
\text { droplets on } \\
\text { hydrophobic glass } \\
\text { cover slips } \\
\text { sol B: excess } \mathrm{I}^{-}\end{array}$ & $\begin{array}{l}30-60 \mu \mathrm{m}, \\
\text { av. } 50 \mu \mathrm{m} \\
\text { sprayed from atom- } \\
\text { izer on cover slips } \\
(\sim 40)\end{array}$ & $\begin{array}{l}\text { 200/drop } \\
10^{-2} \mathrm{M} \mathrm{AgNO}_{3} \\
10^{-4} \mathrm{M} \mathrm{AgNO}_{3} \\
10^{-5} \mathrm{M} \mathrm{AgNO}_{3} \\
\mathrm{H}_{2} \mathrm{O} \\
10^{-6} \mathrm{M} \mathrm{KI} \\
10^{-5} \mathrm{M} \mathrm{KI} \\
10^{-4} \mathrm{M} \mathrm{KI}\end{array}$ & $\begin{array}{l}750 \mathrm{~nm} \\
750 \mathrm{~nm} \\
750 \mathrm{~nm} \\
750 \mathrm{~nm} \\
750 \mathrm{~nm} \\
750 \mathrm{~nm} \\
750 \mathrm{~nm}\end{array}$ & $\begin{array}{l}50 \% \\
50 \% \\
50 \% \\
50 \% \\
50 \% \\
50 \% \\
50 \%\end{array}$ & $\begin{array}{l}252 \mathrm{~K} \\
258 \mathrm{~K} \\
263 \mathrm{~K} \\
264 \mathrm{~K} \\
263 \mathrm{~K} \\
257 \mathrm{~K} \\
256 \mathrm{~K}\end{array}$ & EE62 \\
\hline $\begin{array}{l}\mathrm{AgI}, \\
\mathrm{KNO}_{3}\end{array}$ & In situ precipitation & $\begin{array}{l}\text { Emulsions cooled in } \\
\text { DSC }\end{array}$ & $3 \mu \mathrm{m} \pm 2 \mu \mathrm{m}$ in oil & 1/drop (assumed) & $\begin{array}{l}260 \mathrm{~nm} \\
440 \mathrm{~nm}\end{array}$ & $\begin{array}{l}\text { onset } \\
\sim 50 \%\end{array}$ & $\begin{array}{l}255 \mathrm{~K} \\
251.5 \mathrm{~K}\end{array}$ & Zo08 \\
\hline $\begin{array}{l}\mathrm{AgI}, \\
\mathrm{KNO}_{3}\end{array}$ & In situ precipitation & $\begin{array}{l}\text { Emulsions cooled in } \\
\text { DSC }\end{array}$ & $<3 \mu \mathrm{m}$ in oil & 1/drop (assumed) & $\begin{array}{l}240 \mathrm{~nm} \\
240 \mathrm{~nm}\end{array}$ & $\begin{array}{l}\text { onset } \\
\sim 50 \%\end{array}$ & $\begin{array}{l}255 \mathrm{~K} \\
251 \mathrm{~K}\end{array}$ & $\operatorname{Ag} 82$ \\
\hline $\begin{array}{l}\mathrm{AgI} \\
\mathrm{KNO}_{3}\end{array}$ & In situ precipitation & Bulk cooled in DSC & $1 \mathrm{~cm}^{3}$ & $\begin{array}{l}10^{10} / \text { sample } \\
\text { (assumed) }\end{array}$ & $200 \mathrm{~nm}$ & onset & $269.5 \mathrm{~K}$ & Ag82 \\
\hline $\begin{array}{l}\mathrm{AgI} \\
\mathrm{NaNO}_{3}\end{array}$ & $\begin{array}{l}\text { Precipitation in high- } \\
\text { viscosity silicone oil }\end{array}$ & $\begin{array}{l}\text { Droplets embedded } \\
\text { in oil, cooling at } \\
1 \mathrm{~K} \mathrm{~min}^{-1}\end{array}$ & $100-120 \mu \mathrm{m}$ & Not known & $\begin{array}{l}\text { Not } \\
\text { known }\end{array}$ & $50 \%$ & $257 \mathrm{~K}$ & Ho61 \\
\hline AgI & $\begin{array}{l}\text { Heated wire } \\
\text { coated with AgI }\end{array}$ & $\begin{array}{l}\text { Chamber with falling } \\
\text { droplets; } \\
1 \mathrm{~cm} \text { coagulation re- } \\
\text { gion; particles added } \\
\text { at } T>273 \mathrm{~K}\end{array}$ & $\begin{array}{l}40-160 \mu \mathrm{m} ; \\
\text { av. } 100 \mu \mathrm{m} \\
\text { stable stream }\end{array}$ & $\begin{array}{l}\text { 100/drop, } \\
\text { captured in coagu- } \\
\text { lation } \\
\text { region }\end{array}$ & $\begin{array}{l}30 \mathrm{~nm} \\
30 \mathrm{~nm}\end{array}$ & $\begin{array}{l}<1 \% \\
50 \%\end{array}$ & $\begin{array}{l}263 \mathrm{~K} \\
256 \mathrm{~K}\end{array}$ & SG72 \\
\hline $\begin{array}{l}\mathrm{AgI}- \\
\mathrm{AgCl}\end{array}$ & $\begin{array}{l}\text { Burning acetone- } \\
\text { based solutions }\end{array}$ & $\begin{array}{l}\text { Cloud chamber } \\
C_{\mathrm{D}}<400 \mathrm{~cm}^{-3}\end{array}$ & $\begin{array}{l}\text { CCN activation } \\
\text { of } \mathrm{AgI} \text { particles } \\
(>50 \%) \\
\text { at } T>268 \mathrm{~K}\end{array}$ & 1/drop & $\begin{array}{l}30 \mathrm{~nm} \\
30 \mathrm{~nm} \\
30 \mathrm{~nm} \\
30 \mathrm{~nm} \\
30 \mathrm{~nm} \\
70 \mathrm{~nm} \\
70 \mathrm{~nm} \\
70 \mathrm{~nm} \\
70 \mathrm{~nm} \\
70 \mathrm{~nm}\end{array}$ & $\begin{array}{l}0.05 \% \\
0.5 \% \\
0.8 \% \\
2 \% \\
5 \% \\
0 \% \\
0.01 \% \\
0.1 \% \\
0.2 \% \\
1 \%\end{array}$ & $\begin{array}{l}267 \mathrm{~K} \\
265 \mathrm{~K} \\
263 \mathrm{~K} \\
261 \mathrm{~K} \\
257 \mathrm{~K} \\
267 \mathrm{~K} \\
265 \mathrm{~K} \\
263 \mathrm{~K} \\
261 \mathrm{~K} \\
257 \mathrm{~K}\end{array}$ & DM95 \\
\hline
\end{tabular}


Table 1. Continued.

\begin{tabular}{|c|c|c|c|c|c|c|c|c|}
\hline $\mathrm{AgI}$ & Used as is & $\begin{array}{l}\text { Suspension in } \\
\text { U-shaped glass cap- } \\
\text { illary tube with ca. } \\
0.5 \mathrm{~mm} \text { diameter }\end{array}$ & $0.01 \mathrm{~g} \mathrm{H}_{2} \mathrm{O}$ & $\begin{array}{l}\text { Many particles } \\
\text { refreeze experi- } \\
\text { ments at } T_{\text {const }}\end{array}$ & $10 \mu \mathrm{m}$ & $\begin{array}{l}1 \mathrm{~s} \\
30 \mathrm{~s} \\
15 \mathrm{~min} \\
2 \mathrm{~h}\end{array}$ & $\begin{array}{l}264 \mathrm{~K} \\
266 \mathrm{~K} \\
268 \mathrm{~K} \\
270 \mathrm{~K}\end{array}$ & VB84 \\
\hline AgI & $99.95 \%$ AR grade & $\begin{array}{l}\text { Test tube filled with } \\
\text { suspension, cooled } \\
\text { with } 0.1 \mathrm{~K} \mathrm{~min}^{-1}\end{array}$ & $0.25 \mathrm{~mL}$ suspension & $\begin{array}{l}0.25 \mathrm{mg} \text { per } \\
0.25 \mathrm{~mL} \\
\text { suspension }\end{array}$ & $\sim 55 \mu \mathrm{m}$ & $\begin{array}{l}\text { Repeated } \\
\text { bulk } \\
\text { sample } \\
\text { freezing }\end{array}$ & $270.2 \mathrm{~K}$ & $\mathrm{~Pa} 86$ \\
\hline $\begin{array}{l}\mathrm{AgI}- \\
\mathrm{AgCl}\end{array}$ & $\begin{array}{l}65: 35 \mathrm{~mol} \% \\
\mathrm{AgI} \text { and } \mathrm{AgCl} \\
\text { melted together, then } \\
\text { quenched to RT, } \\
\text { powdered and sieved. }\end{array}$ & $\begin{array}{l}\text { Test tube filled with } \\
\text { suspension, cooled } \\
\text { with } 0.1 \mathrm{~K} \mathrm{~min}^{-1}\end{array}$ & $0.25 \mathrm{~mL}$ suspension & $\begin{array}{l}0.25 \mathrm{mg} \text { per } \\
0.25 \mathrm{~mL} \\
\text { suspension }\end{array}$ & $\sim 55 \mu \mathrm{m}$ & $\begin{array}{l}\text { Repeated } \\
\text { bulk } \\
\text { sample } \\
\text { freezing }\end{array}$ & $271.97 \mathrm{~K}$ & $\mathrm{~Pa} 86$ \\
\hline $\mathrm{AgI}$ & - & $\begin{array}{l}\text { Layer mounted } \\
\text { on thermoelectric } \\
\text { device }\end{array}$ & - & - & - & Threshold & $269 \mathrm{~K}$ & $\mathrm{Da} 75$ \\
\hline $\begin{array}{l}3 \mathrm{AgI} \bullet \\
\mathrm{NH}_{4} \mathrm{I} \bullet \\
\mathrm{H}_{2} \mathrm{O}\end{array}$ & $\begin{array}{l}\text { From aqueous solu- } \\
\text { tion of } \mathrm{AgI} \text { and } \mathrm{NH}_{4} \mathrm{I}\end{array}$ & $\begin{array}{l}\text { Layer mounted } \\
\text { on thermoelectric } \\
\text { device }\end{array}$ & - & - & - & Threshold & $272 \mathrm{~K}$ & Da75 \\
\hline $\begin{array}{l}\mathrm{AgI}, \\
\mathrm{KNO}_{3}\end{array}$ & $\begin{array}{l}\text { Precipitated suspen- } \\
\text { sion, atomized and } \\
\text { size selected }\end{array}$ & $\begin{array}{l}\text { IMCA-ZINC cham- } \\
\text { ber, activation sec- } \\
\text { tion followed by } \\
\text { nucleation section }\end{array}$ & $\begin{array}{l}20 \mu \mathrm{m} \text { from AgI } \\
\text { particles activated } \\
\text { at } T>273 \mathrm{~K}, \\
S_{\mathrm{W}}>20 \%\end{array}$ & $\begin{array}{l}\text { 1/drop, } 3 \mathrm{~s} \\
\text { residence time } \\
1 / \text { drop, } 10 \mathrm{~s} \\
\text { residence time }\end{array}$ & $\begin{array}{l}200 \mathrm{~nm} \\
200 \mathrm{~nm} \\
200 \mathrm{~nm} \\
400 \mathrm{~nm} \\
20 \mathrm{~nm} \\
30 \mathrm{~nm} \\
40 \mathrm{~nm} \\
50 \mathrm{~nm} \\
200 \mathrm{~nm} \\
400 \mathrm{~nm}\end{array}$ & $\begin{array}{l}10 \% \\
50 \% \\
100 \% \\
50 \% \\
50 \% \\
50 \% \\
50 \% \\
50 \% \\
50 \% \\
50 \%\end{array}$ & $\begin{array}{l}265 \mathrm{~K} \\
262 \mathrm{~K} \\
255 \mathrm{~K} \\
263 \mathrm{~K} \\
236.5 \mathrm{~K} \\
259 \mathrm{~K} \\
264 \mathrm{~K} \\
264 \mathrm{~K} \\
264 \mathrm{~K} \\
264 \mathrm{~K}\end{array}$ & This study \\
\hline
\end{tabular}

a clear negative influence of the surface charge on the nucleation ability of silver iodide.

Gokhale and Goold (1968) used a cold stage to perform contact nucleation experiments (see Table 2). They sprinkled AgI particles on supercooled droplets on a hydrophobic plate at $268 \mathrm{~K}$. They observed that the particles $(5-400 \mu \mathrm{m}$ in diameter) remained on the surface of the drops and initiated freezing at the initial stage temperature of $268 \mathrm{~K}$. However, they did not quantify the number of particles present, which precludes an evaluation in terms of surface area. They performed similar experiments for an AgI smoke produced from an $\mathrm{AgI}$ string generator with particle diameters from 50 to $100 \mathrm{~nm}$. These particles initiated freezing of $50 \%$ of droplets at $263 \mathrm{~K}$ when the stage was cooled at a rate of $1.3 \mathrm{~K} \mathrm{~min}^{-1}$. Gokhale and Goold (1968) concluded that these freezing temperatures are $5-10 \mathrm{~K}$ higher than the ones observed by Hoffer (1961) for droplets embedded in an oil with immersed AgI particles (see Sect. 3.2.2) and attributed it to an enhanced freezing probability for dry particles on a surface compared with particles immersed in the droplet. However, a strict comparison is not possible because in both studies information is lacking to quantify the surface area present per droplet. In a follow-up study, Gokhale and Lewinter (1971) monitored the freezing process of $2 \mathrm{~mm}$ water droplets with a movie camera and observed that nucleation was initiated at the point of particle contact and continued from there over the entire surface of the drop. The interior of the drop froze at a much slower rate.

Bryant et al. (1959) investigated the development of ice crystals on AgI films with a microscope (see Table 4). They exposed the samples to increasing relative humidity at different temperatures. For $T>269 \mathrm{~K}$, only water droplets formed. For $T=261-269 \mathrm{~K}$, supersaturation with respect to water was required for ice crystals to grow. For $T<261 \mathrm{~K}$, supersaturation with respect to ice sufficed. Crystals were observed to form on specific sites which darkened with increasing exposure to white light from the microscope and seemed to be preferred centers for the decomposition of silver iodide to metallic silver and may mark the sites of emergent dislocations.

Similarly, Anderson and Hallett (1976) investigated large cleaved AgI crystals by microscopy when crystals were exposed to increasing humidity (see Table 4). In accordance with Bryant et al. (1959), they observed additional ice crystal nucleation when the AgI surface was illuminated by white light compared with red light. At one temperature, each nucleation site required a different ice supersaturation for activation, consistent with preferred nucleation at steps or some geometrical irregularity.

Using a microscope, Edwards and Evans (1960) observed the ice nucleation activity of a fine AgI aerosol on a gold substrate in deposition mode (see Table 4). The AgI parti- 
Table 2. Contact freezing studies with $\mathrm{AgI}$ and related salts. IN: ice nuclei; $D_{\mathrm{D}}$ : droplet diameter; $C_{\mathrm{p}}$ : particle concentration; $D_{\mathrm{p}}$ : particle diameter; $T_{\mathrm{f}}$ : freezing temperature; $C_{\mathrm{D}}$ : droplet concentration. References: GG68 - Gokhale and Goold (1968); GL71 - Gokhale and Lewinter (1971); SG72 - Sax and Goldsmith (1972); La78 - Langer et al. (1978); SF79 - Schaller and Fukuta (1979); DM95 - DeMott (1995); Na16 - Nagare et al. (2016).

\begin{tabular}{|c|c|c|c|c|c|c|c|c|}
\hline IN & Preparation & Setup & $D_{\mathrm{D}} \&$ prep & $C_{\mathrm{p}}$ & $D_{\mathrm{p}}$ & Activation & $T_{\mathrm{f}}$ & Refs \\
\hline Ag mixed with $\mathrm{NaI}$ & $\begin{array}{l}\text { Burner smoke from } \\
\text { AgI string } \\
\text { generator }\end{array}$ & $\begin{array}{l}\text { Droplets on } \\
\text { hydrophobic } \\
\text { plate, cooling at } \\
1.3 \mathrm{~K} \mathrm{~min}^{-1}\end{array}$ & $2.7 \mathrm{~mm}$ deposited & $\begin{array}{l}\text { Smoke (introduced } \\
\text { into chamber at } \\
268 \mathrm{~K})\end{array}$ & $50-100 \mathrm{~nm}$ & $\begin{array}{l}4 \% \\
50 \%\end{array}$ & $\begin{array}{l}268 \mathrm{~K} \\
263 \mathrm{~K}\end{array}$ & GG68 \\
\hline AgI & Crushed powder & $\begin{array}{l}\text { Droplets on } \\
\text { hydrophobic plate }\end{array}$ & $2.7 \mathrm{~mm}$ deposited & $\begin{array}{l}\text { Many particles } \\
\text { (sprinkled on drops } \\
\text { at } 268 \mathrm{~K} \text { ) }\end{array}$ & $\begin{array}{l}4-10 \mu \mathrm{m} \\
5-20 \mu \mathrm{m} \\
100-400 \mu \mathrm{m}\end{array}$ & $\begin{array}{l}100 \% \\
100 \% \\
100 \%\end{array}$ & $\begin{array}{l}268 \mathrm{~K} \\
268 \mathrm{~K} \\
268 \mathrm{~K}\end{array}$ & GG68 \\
\hline AgI & $\begin{array}{l}\text { Purified grade used } \\
\text { as is }\end{array}$ & $\begin{array}{l}\text { Droplets on } \\
\text { hydrophobic plate }\end{array}$ & $2 \mathrm{~mm}$ deposited & $\begin{array}{l}\text { Many particles } \\
\text { (sprinkled on drops } \\
\text { at } 268 \mathrm{~K} \text { ) }\end{array}$ & micron size & $\begin{array}{l}\text { Freezing } \\
\text { within } \\
16-47 \mathrm{~ms}\end{array}$ & $268 \mathrm{~K}$ & GL71 \\
\hline AgI & $\begin{array}{l}\text { Heated wire coated } \\
\text { with AgI }\end{array}$ & $\begin{array}{l}\text { Chamber with } \\
\text { falling droplets; } \\
1 \mathrm{~cm} \text { coagulation } \\
\text { region; particles } \\
\text { added at } T_{\mathrm{f}}\end{array}$ & $\begin{array}{l}40-160 \mu \mathrm{m} ; \\
\text { av. } 100 \mu \mathrm{m} \\
\text { stable stream }\end{array}$ & $\begin{array}{l}\text { 100/drop, captured } \\
\text { in coagulation } \\
\text { region }\end{array}$ & $\begin{array}{l}30 \mathrm{~nm} \\
30 \mathrm{~nm} \\
30 \mathrm{~nm}\end{array}$ & $\begin{array}{l}1 \% \\
50 \% \\
100 \%\end{array}$ & $\begin{array}{l}263 \mathrm{~K} \\
258 \mathrm{~K} \\
256 \mathrm{~K}\end{array}$ & SG72 \\
\hline AgI & $\begin{array}{l}\text { Heated wire } \\
\text { coated with } \\
\text { AgI }\end{array}$ & $\begin{array}{l}\text { Chamber, } \\
\text { particles added at } \\
\text { target tempera- } \\
\text { ture }\end{array}$ & $\begin{array}{l}1 \mathrm{~mm} \\
\text { on tip of fiber in cham- } \\
\text { ber }\end{array}$ & $\begin{array}{l}10^{5} / \text { drop } \\
<250 / \text { drop }\end{array}$ & $\begin{array}{l}30 \mathrm{~nm} \\
30 \mathrm{~nm}\end{array}$ & $\begin{array}{l}50-100 \% \\
50-100 \%\end{array}$ & $\begin{array}{l}268 \mathrm{~K} \\
263 \mathrm{~K}\end{array}$ & SG72 \\
\hline AgI & $\begin{array}{l}\text { Thermally (from } \\
\text { molten AgI) }\end{array}$ & $\begin{array}{l}\text { Cloud chamber, } \\
\text { Residence time: } \\
120 \mathrm{~s}(20-300 \mathrm{~s})\end{array}$ & $\begin{array}{l}(1-10 \mu \mathrm{m}) \\
\text { av. } 6 \mu \mathrm{m} \text { activated from } \\
\mathrm{NaCl} \text { aerosol, } \\
C_{\mathrm{D}}=4 \times 10^{4} \mathrm{~cm}^{-3}\end{array}$ & $100-1000 \mathrm{~cm}^{-3}$ air & $\begin{array}{l}20 \mathrm{~nm} \\
40 \mathrm{~nm} \\
60 \mathrm{~nm} \\
80 \mathrm{~nm} \\
100 \mathrm{~nm} \\
120 \mathrm{~nm}\end{array}$ & $\begin{array}{l}1.2 \% \\
15 \% \\
28 \% \\
41 \% \\
46 \% \\
47 \%\end{array}$ & $\begin{array}{l}257-258 \mathrm{~K} \\
257-258 \mathrm{~K} \\
257-258 \mathrm{~K} \\
257-258 \mathrm{~K} \\
257-258 \mathrm{~K} \\
257-258 \mathrm{~K}\end{array}$ & $\mathrm{La78}$ \\
\hline AgI, & $\begin{array}{l}\text { Reagent grade, } \\
\text { heated on iron } \\
\text { plate }\end{array}$ & $\begin{array}{l}\text { Wedge-shaped ice } \\
\text { thermal diffusion } \\
\text { chamber }\end{array}$ & $\begin{array}{l}\text { Small fog droplets } \\
\text { activated from } \mathrm{NH}_{4} \mathrm{Cl} \\
\text { particles }\end{array}$ & $1 /$ drop & $\begin{array}{l}\text { Average: } \\
300 \mathrm{~nm}\end{array}$ & Not known & $267 \mathrm{~K}$ & SF79 \\
\hline $\mathrm{AgI}-\mathrm{AgCl}$ & $\begin{array}{l}\text { Burning acetone- } \\
\text { based solutions }\end{array}$ & $\begin{array}{l}\text { Isothermal cloud } \\
\text { chamber }(960 \mathrm{~L}) \\
t_{\mathrm{exp}}=3-30 \mathrm{~min} \\
C_{\mathrm{D}}=4300 \mathrm{~cm}^{-3}\end{array}$ & $\begin{array}{l}8 \mu \mathrm{m}(1-16 \mu \mathrm{m}) \\
\text { continuously produced } \\
\text { by nebulizing water }\end{array}$ & 1/drop (nominal) & $\begin{array}{l}30 \mathrm{~nm} \\
30 \mathrm{~nm} \\
30 \mathrm{~nm} \\
30 \mathrm{~nm} \\
30 \mathrm{~nm} \\
70 \mathrm{~nm} \\
70 \mathrm{~nm} \\
70 \mathrm{~nm} \\
70 \mathrm{~nm} \\
70 \mathrm{~nm}\end{array}$ & $\begin{array}{l}0.04 \% \\
6.6 \% \\
12.2 \% \\
24.3 \% \\
34.4 \% \\
0.2 \% \\
39.8 \% \\
54.6 \% \\
45.8 \% \\
65.0 \%\end{array}$ & $\begin{array}{l}267 \mathrm{~K} \\
265 \mathrm{~K} \\
263 \mathrm{~K} \\
261 \mathrm{~K} \\
257 \mathrm{~K} \\
267 \mathrm{~K} \\
265 \mathrm{~K} \\
263 \mathrm{~K} \\
261 \mathrm{~K} \\
257 \mathrm{~K}\end{array}$ & DM95 \\
\hline $\mathrm{AgI}, \mathrm{KNO}_{3}$ & $\begin{array}{l}\text { Precipitated } \\
\text { suspension } \\
\text { atomized and size } \\
\text { selected }\end{array}$ & $\begin{array}{l}\text { CLINCH } \\
\text { Continuous-flow } \\
\text { diffusion } \\
\text { chamber }\end{array}$ & $\begin{array}{l}80 \mu \mathrm{m} \\
\text { injected in chamber }\end{array}$ & $\begin{array}{l}1 / \text { drop } \\
1 / \text { drop } \\
2 / \text { drop } \\
2 / \text { drop }\end{array}$ & $\begin{array}{l}200 \mathrm{~nm} \\
200 \mathrm{~nm} \\
200 \mathrm{~nm} \\
200 \mathrm{~nm}\end{array}$ & $\begin{array}{l}50 \% \\
100 \% \\
50 \% \\
100 \%\end{array}$ & $\begin{array}{l}248 \mathrm{~K} \\
246 \mathrm{~K} \\
258 \mathrm{~K} \\
250 \mathrm{~K}\end{array}$ & $\mathrm{Na} 16$ \\
\hline
\end{tabular}

cles typically had diameters $<15 \mathrm{~nm}$ and were produced by reacting an $\mathrm{Ag}$ aerosol with iodine vapor. At $98 \% \mathrm{RH}$ and temperatures of 262,258 and $255 \mathrm{~K}$, only a small fraction of particles $(<0.5 \%)$ was active in deposition mode.

Zimmermann et al. (2007) studied heterogeneous ice nucleation by $\mathrm{AgI}$ in an environmental scanning electron microscope (ESEM) in deposition and condensation mode (see Tables 3 and 4). They used p.a. grade AgI that they ground to obtain particles in the size range from 1 to $10 \mu \mathrm{m}$. Experiments were performed by increasing the vapor pressure in the sample chamber at a constant temperature. First ice formation in condensation mode was observed at a temperature of $268 \mathrm{~K}$ and in deposition mode at $264 \mathrm{~K}$.

\subsubsection{Experiments with droplets embedded in oil}

Zobrist et al. (2008) and Aguerd et al. (1982) investigated immersion freezing in water-in-oil emulsions. Their results are shown in Fig. 2 as purple triangles (Zobrist et al., 2008) and purple squares (Aguerd et al., 1982). Details of the experiments are given in Table 1 . AgI particles were prepared in situ by precipitating a silver nitrate solution and a potassium iodide solution in the presence of an oil containing a surfactant for emulsification. The freezing experiments were carried out in a differential scanning calorimeter (DSC) immediately after preparation. In the DSC thermograms of Zobrist et al. (2008) and Aguerd et al. (1982), a heterogeneous and a homogeneous freezing peak appeared. 
Table 3. Condensation freezing studies. IN: ice nuclei; $D_{\mathrm{D}}$ : droplet diameter; $C_{\mathrm{p}}$ : particle concentration; $D_{\mathrm{p}}$ : particle diameter; $T_{\mathrm{f}}$ : freezing temperature. $S_{\mathrm{w}}$ : supersaturation with respect to water. References: MH59 - Mason and van den Heuvel, 1959; SF79 - Schaller and Fukuta, 1979; EE60 - Edwards and Evans, 1960; DM95 - DeMott, 1995; Zi07 - Zimmermann et al., 2007; ESEM - environmental scanning electron microscopy.

\begin{tabular}{|c|c|c|c|c|c|c|c|c|}
\hline IN & Preparation & Setup & $D_{\mathrm{D}} \&$ prep & $C_{\mathrm{p}}$ & $D_{\mathrm{p}}$ & Activation & $T_{\mathrm{f}}$ & Refs \\
\hline $\mathrm{AgI}$ & $\begin{array}{l}\text { AgI smoke produced by } \\
\text { heating AgI }\end{array}$ & $\begin{array}{l}\text { Aerosol introduced } \\
\text { into an ice diffusion } \\
\text { chamber }\end{array}$ & $\begin{array}{l}\text { Activation at water } \\
\text { saturation }\end{array}$ & 1/drop & & Threshold & $267 \mathrm{~K}$ & MH59 \\
\hline $\mathrm{AgI}$ & $\begin{array}{l}\text { Reagent grade heated } \\
\text { on iron plate }\end{array}$ & $\begin{array}{l}\text { Wedge-shaped ice } \\
\text { thermal diffusion } \\
\text { chamber }\end{array}$ & $\begin{array}{l}\text { Small fog droplets } \\
\text { activated from AgI at } \\
S_{\mathrm{W}}=12.5 \%\end{array}$ & 1/drop & Av: $300 \mathrm{~nm}$ & $\begin{array}{l}1.3 \% \\
6.4 \%\end{array}$ & $\begin{array}{l}268.5 \mathrm{~K} \\
267 \mathrm{~K}\end{array}$ & SF79 \\
\hline $\mathrm{AgI}-\mathrm{AgCl}$ & $\begin{array}{l}\text { Burning acetone-based } \\
\text { solutions }\end{array}$ & $\begin{array}{l}\text { Dynamic (controlled } \\
\text { expansion) cloud } \\
\text { chamber }\end{array}$ & Cloud point & 1/drop & $30-70 \mathrm{~nm}$ & $\begin{array}{l}2 \times 10^{-4} \\
2 \times 10^{-3}\end{array}$ & $\begin{array}{l}266 \mathrm{~K} \\
260 \mathrm{~K}\end{array}$ & DM95 \\
\hline AgI, p.a. & Ground & $\begin{array}{l}\text { ESEM, increasing RH } \\
\text { in steps of } 0.13 \mathrm{hPa} \\
(5-10 \mathrm{~min})\end{array}$ & $\begin{array}{l}\text { Activation at } \\
S_{\mathrm{W}}=8-11 \%\end{array}$ & 1/drop & $1-10 \mu \mathrm{m}$ & Threshold & $268 \mathrm{~K}$ & $\mathrm{Zi07}$ \\
\hline
\end{tabular}

Table 4. Deposition nucleation studies. IN: ice nuclei; $\mathrm{RH}_{\mathrm{a}}$ : activation relative humidity; $\mathrm{RH}_{i}$ : relative humidity with respect to ice; $\mathrm{RH}_{\mathrm{w}}$ : relative humidity with respect to water; $T_{\mathrm{a}}$ : activation temperature. References: Br59 - Bryant et al. (1959); AH76 - Anderson and Hallett (1967); EE60 - Edwards and Evans (1960); Zi07 - Zimmermann et al. (2007); MH59 - Mason and van den Heuvel (1959); SF79 Schaller and Fukuta (1979); DM95 - DeMott (1995). ESEM - environmental scanning electron microscopy.

\begin{tabular}{|c|c|c|c|c|c|c|c|}
\hline IN & Preparation & Setup & AgI crystals & $\begin{array}{l}\text { Nucleation of } \\
\text { crystals }\end{array}$ & $\mathrm{RH}_{\mathrm{a}}$ & $T_{\mathrm{a}}$ & Refs \\
\hline AgI & $\begin{array}{l}\text { AgI layer prepared by oxidizing } \\
\text { silver by iodine vapor }\end{array}$ & $\begin{array}{l}\text { Crystal in temperature and } \\
\text { RH-controlled chamber } \\
\text { observed by microscopy }\end{array}$ & Single crystal & $\begin{array}{l}\text { At special sites of } \\
\text { crystal }\end{array}$ & $\begin{array}{l}>\mathrm{RH}_{\mathrm{w}} \\
>112 \% \mathrm{RH}_{i}\end{array}$ & $\begin{array}{l}269 \mathrm{~K} \\
<261 \mathrm{~K}\end{array}$ & Br59 \\
\hline AgI & $\begin{array}{l}\text { Large cleaved crystals grown } \\
\text { from solution }\end{array}$ & $\begin{array}{l}\text { Crystal in temperature and } \\
\text { RH-controlled chamber } \\
\text { observed by microscopy }\end{array}$ & Single crystal & $\begin{array}{l}\text { At special sites of } \\
\text { crystals }\end{array}$ & $>102 \% \mathrm{RH}_{i}$ & $\leq 268 \mathrm{~K}$ & AH76 \\
\hline AgI & $\begin{array}{l}\text { Ag aerosol reacting with iodine } \\
\text { vapor }\end{array}$ & $\begin{array}{l}\text { Particles on gold disc on an } \\
\text { RH-controlled, liquid-cooled } \\
\text { stage observed by microscopy }\end{array}$ & $\leq 15 \mathrm{~nm}$ diameter & $\begin{array}{l}<0.5 \% \\
<0.5 \% \\
<0.5 \%\end{array}$ & $\begin{array}{l}98 \% \mathrm{RH}_{\mathrm{W}} \\
98 \% \mathrm{RH}_{\mathrm{W}} \\
98 \% \mathrm{RH}_{\mathrm{W}}\end{array}$ & $\begin{array}{l}262 \mathrm{~K} \\
258 \mathrm{~K} \\
255 \mathrm{~K}\end{array}$ & EE60 \\
\hline AgI, p.a. & Ground & $\begin{array}{l}\text { ESEM, increasing RH in steps } \\
\text { of } 0.13 \mathrm{hPa}(5-10 \mathrm{~min})\end{array}$ & $1-10 \mu \mathrm{m}$ & $\begin{array}{l}\text { Threshold activa- } \\
\text { tion }\end{array}$ & $107 \% \mathrm{RH}_{i}$ & $264 \mathrm{~K}$ & $\mathrm{Zi07}$ \\
\hline AgI & $\begin{array}{l}\text { AgI smoke produced by heating } \\
\text { AgI }\end{array}$ & $\begin{array}{l}\text { Aerosol introduced into an ice } \\
\text { diffusion chamber }\end{array}$ & - & - & $>112 \% \mathrm{RH}_{i}$ & $<261 \mathrm{~K}$ & MH59 \\
\hline AgI & $\begin{array}{l}\text { Reagent grade heated on iron } \\
\text { plate }\end{array}$ & $\begin{array}{l}\text { Wedge-shaped ice thermal } \\
\text { diffusion chamber }\end{array}$ & Av. $300 \mathrm{~nm}$ diameter & $\begin{array}{l}1.3 \% \\
1.3 \% \\
6.4 \% \\
6.4 \%\end{array}$ & $\begin{array}{l}108 \% \mathrm{RH}_{i} \\
105 \% \mathrm{RH}_{i} \\
109 \% \mathrm{RH}_{i} \\
107 \% \mathrm{RH}_{i}\end{array}$ & $\begin{array}{l}264 \mathrm{~K} \\
258 \mathrm{~K} \\
262 \mathrm{~K} \\
258 \mathrm{~K}\end{array}$ & SF79 \\
\hline $\mathrm{AgI}-\mathrm{AgCl}$ & $\begin{array}{l}\text { Burning acetone-based } \\
\text { solutions }\end{array}$ & $\begin{array}{l}\text { Dynamic (controlled } \\
\text { expansion) cloud chamber }\end{array}$ & $30-70 \mathrm{~nm}$ particles & $\begin{array}{l}5 \times 10^{-5} \\
10^{-4} \\
2 \times 10^{-4} \\
7 \times 10^{-4} \\
1.5 \times 10^{-3} \\
2 \times 10^{-3}\end{array}$ & $\begin{array}{l}104 \% \mathrm{RH}_{i} \\
106 \% \mathrm{RH}_{i} \\
107 \% \mathrm{RH}_{i} \\
104 \% \mathrm{RH}_{i} \\
107 \% \mathrm{RH}_{i} \\
112 \% \mathrm{RH}_{i}\end{array}$ & $\begin{array}{l}266 \mathrm{~K} \\
266 \mathrm{~K} \\
266 \mathrm{~K} \\
260 \mathrm{~K} \\
260 \mathrm{~K} \\
260 \mathrm{~K}\end{array}$ & DM95 \\
\hline
\end{tabular}

The presence of the homogeneous freezing peak could be either due to the absence of crystallized AgI in some of the droplets or inactive AgI crystallites. To quantify the surface area present per droplet, crystallization of one spherical particle per droplet was assumed, yielding particle diameters of 200-500 nm, depending on the assumed droplet size. For Zobrist et al. (2008), we assigned the onset of the heterogeneous freezing peak to freezing of $5 \mu \mathrm{m}$ droplets and the maximum to freezing of $3 \mu \mathrm{m}$ droplets. To quantify the surface area of AgI per droplet for Aguerd et al. (1982), an average droplet size of $2 \mu \mathrm{m}$ was assumed. Considering the uncertainties in estimating surface areas per droplet, the results from emulsion freezing experiments are in good agreements with each other and with the study performed with deposited AgI crystallites from Edwards et al. (1962). 
Hoffer (1961) investigated freezing of 100-120 $\mu$ m water droplets embedded in a silicone oil (see Table 1). AgI particles were produced from the reaction of silver nitrate with sodium iodide. He observed a median freezing temperature of $257 \mathrm{~K}$ when the droplets were cooled at a rate of $1 \mathrm{~K} \mathrm{~min}^{-1}$ and concluded that this value is lower by $9 \mathrm{~K}$ compared with results from cold chambers. However, with the given information, a strict comparison is not possible because the surface area of AgI present in a droplet cannot be quantified.

\subsubsection{Cloud chamber experiments}

Among the first to investigate ice nucleation on an AgI aerosol in a cloud chamber were Mason and van den Heuvel (1959) (see Tables 3 and 4). They introduced an AgI aerosol into an ice diffusion chamber and observed that ice crystals nucleated in deposition and in condensation mode by their glittering in a beam of light from a mercury arc lamp. For $T=261$ to $268 \mathrm{~K}$ supersaturation with respect to water was required to produce ice crystals. Above this temperature, only water droplets formed. For $T<261 \mathrm{~K}$ supersaturation of $12 \%$ with respect to ice was sufficient to form ice crystals. The size of the AgI particles is not specified in this study. Therefore, it is not clear whether the relative humidity threshold for condensation freezing is limited by droplet activation.

Edwards and Evans (1960) investigated condensation freezing of an AgI aerosol in a cloud chamber produced by reacting an Ag aerosol with iodine vapor (see Table 3). They noted that condensation freezing was indeed limited by droplet activation for their aerosol. A supersaturation of $20 \%$ with respect to water was needed to activate the AgI particles with typical diameters from 12 to $20 \mathrm{~nm}$. Condensation freezing occurred up to $267 \mathrm{~K}$. The activity of this aerosol was also tested when it was deposited on a substrate (see Table 4). At $98 \% \mathrm{RH}$ and temperatures of 262, 258 and $255 \mathrm{~K}$, a small fraction of particles $(<0.005)$ was active in deposition mode.

Sax and Goldsmith (1972) performed immersion and contact freezing experiments in a cloud chamber (see Tables 1 and 2). Results are shown as filled and open blue diamonds in Fig. 2, respectively. Freely falling droplets with diameters from 40 to $160 \mu \mathrm{m}$ (average: $100 \mu \mathrm{m}$ ) intercepted a horizontal aerosol stream of $5 \times 10^{6} \mathrm{~cm}^{-3} \mathrm{AgI}$ particles with a $30 \mathrm{~nm}$ diameter (size range from 10 to $40 \mathrm{~nm}$ ) for $0.04 \mathrm{~s}(1 \mathrm{~cm}$ in vertical extent). The aerosol was produced by heating an AgIcoated resistance wire to $T=973 \mathrm{~K}$ in a nitrogen stream. For contact freezing experiments the droplets were brought into thermal equilibrium before intercepting the aerosol stream. After coagulation with the AgI particles, the droplets proceeded into an observation chamber, where frozen droplets were distinguished visually from liquid ones. The collision of $100 \mu \mathrm{m}$ droplets with $30 \mathrm{~nm}$ particles is dominated by Brownian motion. Assuming a collision efficiency of ca. 0.3, around 100 particles would be captured by the droplet (note that this number is higher than the collection of only 1 particle estimated by Sax and Goldsmith, 1972). For immersion freezing experiments, the droplets passed the aerosol stream at $T>273 \mathrm{~K}$ before they were cooled to the target temperature. The residence time in the chamber was around $4 \mathrm{~s}$. Immersion freezing occurred at a $2 \mathrm{~K}$ lower temperature than contact freezing.

Langer et al. (1978) investigated contact freezing of monodisperse AgI aerosols in a cloud chamber (open red circles in Fig. 2 and Table 2). Silver iodide aerosol was generated thermally by passing dry air over molten AgI at temperatures up to $100 \mathrm{~K}$ above the AgI melting point of $831 \mathrm{~K}$. $\mathrm{A} \mathrm{NaCl}$ aerosol was used to generate the liquid cloud in the chamber. During operation, there was a continuous stream of $\mathrm{AgI}$ aerosol and $\mathrm{NaCl}$ aerosol. The nucleating fraction and freezing temperatures were observed to increase with increasing particle size. Particles with diameters $<20 \mathrm{~nm}$ and $<10 \mathrm{~nm}$ were essentially inactive at temperatures of 259 and $253 \mathrm{~K}$, respectively.

Schaller and Fukuta (1979) investigated deposition, condensation and contact freezing of AgI in their ice thermal diffusion chamber (see Tables 2, 3 and 4). The AgI aerosol was produced by heating an AgI powder on an iron plate. The smoke was introduced into the chamber and frozen fractions were evaluated after $1 \mathrm{~min}$. They observed deposition nucleation up to $264 \mathrm{~K}$ and condensation freezing up to $268.5 \mathrm{~K}$ (frozen fraction of $1.3 \%$ after $1 \mathrm{~min}$ ). The onset temperature and the frozen fraction for condensation freezing increased with increasing supersaturation. Contact freezing was observed between 265 and $267 \mathrm{~K}$. This temperature range nearly coincides with the one for condensation freezing. For comparison, Schaller and Fukuta (1979) performed an experiment in immersion mode with the AgI aerosol activated to cloud droplets above the ice nucleation threshold temperature. When the fog had formed, the chamber was cooled. No difference in ice nucleation behavior was observed for this procedure compared to condensation freezing experiments.

DeMott (1995) investigated the efficiency of ice formation with silver-iodide-type aerosols depending on ice nucleation mode with the aim to reproduce ice seeding conditions as closely as possible in cloud chambers (see Tables 1-4). He used a field-scale solution combustion device to produce $\mathrm{AgI}$ and $\mathrm{AgI}-\mathrm{AgCl}$ aerosols. This generator produces AgI aerosols by burning AgI-acetone-ammonium iodide-water solutions in a propane flame. To produce AgI$\mathrm{AgCl}$ aerosols, 20-30 mole \% ammonium perchlorate were added to the standard solution. Contact freezing experiments were performed in an isothermal cloud chamber, which isolates an artificially generated cloud at a supercooled temperature. The cloud is continuously replenished during an experiment to maintain a constant cloud droplet concentration. Total nominal droplet concentrations were either $2100 \mathrm{~cm}^{-3}$ or $4300 \mathrm{~cm}^{-3}$ in individual experiments. Results are shown in Fig. 2 for 30 and $70 \mathrm{~nm}$ particles as black open squares. 
For immersion freezing experiments, clouds were formed on $\mathrm{AgI}-\mathrm{AgCl}$ aerosols at $T>268 \mathrm{~K}$ in a dynamic (controlled expansion) cloud chamber. Continuous expansion led to freezing at $257 \mathrm{~K}$, as indicated by black filled squares in Fig. 2. DeMott (1995) concluded that immersion freezing is more than 1 order of magnitude less efficient than contact freezing for $\mathrm{AgI}-\mathrm{AgCl}$ aerosols.

\subsubsection{Bulk experiments}

The highest freezing temperatures were obtained for bulk AgI suspensions (see Table 1). Aguerd et al. (1982) investigated a $1 \mathrm{~cm}^{3}$ bulk sample by mixing $0.01 \mathrm{M} \mathrm{AgNO}_{3}$ and $0.01 \mathrm{M} \mathrm{KI}$, for which they determined freezing at $269.5 \mathrm{~K}$.

Vonnegut and Baldwin (1984) investigated the kinetics of ice nucleation by measuring the time to freezing at a constant temperature of a bulk sample with immersed AgI particles of $1 \mu \mathrm{m}$ diameter. While freezing occurred with an average nucleation time of $1 \mathrm{~s}$ at $264 \mathrm{~K}$, it took more than $10000 \mathrm{~s}$ to nucleate the sample at $270 \mathrm{~K}$. This shows the stochastic nature of ice nucleation and that nucleation time has to be considered together with freezing temperature and surface area for comparisons between different studies. Palanisamy et al. (1986a) investigated bulk samples in test tubes cooled at a rate of $0.1 \mathrm{~K} \mathrm{~min}^{-1}$ and observed freezing of pure AgI particles at $270.62 \mathrm{~K}$ and freezing of $\mathrm{AgI}-\mathrm{AgCl}$ cubic solid solutions at an even higher temperature of $271.97 \mathrm{~K}$.

Davis et al. (1975) reported freezing of water in contact with $3 \mathrm{AgI} \cdot \mathrm{NH}_{4} \mathrm{I} \cdot 6 \mathrm{H}_{2} \mathrm{O}$ films at $272 \mathrm{~K}$ compared with freezing at $269 \mathrm{~K}$ for AgI films.

\subsubsection{Continuous-flow diffusion chamber experiments}

Nagare et al. $(2015,2016)$ presented contact freezing experiments performed with the ETH CoLlision Ice Nucleation CHamber (CLINCH) using $80 \mu \mathrm{m}$ diameter droplets, which were exposed to $200 \mathrm{~nm}$ and $400 \mathrm{~nm}$ diameter AgI particles. These particles were prepared by mixing $\mathrm{AgNO}_{3}$ and $\mathrm{KI}$ solutions. The suspension was atomized and the droplets were dried and size selected. Droplet residence times in the chamber, which was held at ice saturation, were 2 and $4 \mathrm{~s}$. These results are given as open green diamonds in Fig. 2. Details of the experiments are listed in Table 2. For aerosol concentrations from 500 to $2000 \mathrm{~cm}^{-3}$, low freezing efficiencies with median freezing temperatures of only $T_{\mathrm{M}}=247-248 \mathrm{~K}$ were measured. At these concentrations, the droplets collected on average less than one particle. For a particle concentration of $5000 \mathrm{~cm}^{-3}$ and a $4 \mathrm{~s}$ residence time, the droplets collected on average 2.35 particles and the median freezing temperature was $258 \mathrm{~K}$.

Immersion freezing experiments in the IMCA-ZINC chamber with an AgI aerosol prepared by the same method as for the CLINCH experiments have also been carried out (see Sect. 2). The results of these measurements are given as filled green symbols in Fig. 2. It can be seen that freez- ing efficiencies for the immersion freezing experiments performed with IMCA-ZINC are distinctly higher than for the contact freezing experiments performed with CLINCH, although the same AgI aerosol was used for both experiments. With median freezing temperatures $T_{\mathrm{M}}=262 \mathrm{~K}$ for $200 \mathrm{~nm}$ particles at a $3 \mathrm{~s}$ residence time, the freezing temperatures from IMCA-ZINC are also higher than the ones from immersion freezing studies performed with droplets deposited on substrates and freezing experiments with emulsions. Reasons for this are discussed in the next section.

\section{Discussion}

Figure 2 shows a general trend of increasing freezing temperatures with increasing AgI surface area; however, there are also several exceptions. For a more consistent comparison, instead of freezing temperatures, nucleation rate coefficients expressed in units of, e.g., $\mathrm{cm}^{-2} \mathrm{~s}^{-1}$ should be compared. However, most studies do not provide enough information to determine rates. Freezing temperatures as a function of surface area depend on measurement-specific factors like the frozen fraction they refer to, the nucleation mode and properties of the AgI particles dependent on the preparation method. In the following, relevant factors influencing heterogeneous ice nucleation by AgI will be discussed in more detail.

\subsection{Freezing temperature and frozen fraction}

The freezing temperature, which should characterize the efficiency of an ice-nucleating substance, is not independent of instrumental factors that have to be taken into account when results from different instruments are compared. Some detection methods provide onset temperatures of freezing. These depend on the detection limit of the measurement technique and are higher than median freezing temperatures, which are also often reported. With the IMCA-ZINC setup, freezing temperatures for frozen fractions of $0.1-1$ are measurable. For $200 \mathrm{~nm}$ AgI particles and a 3 s residence time, a median freezing temperature of $262 \mathrm{~K}$ was obtained. A frozen fraction of 0.1 was already reached at $265 \mathrm{~K}$ and a frozen fraction of 1 only at $254 \mathrm{~K}$. Thus, the difference in temperature between a frozen fraction of 0.1 and a fully frozen sample is $8 \mathrm{~K}$. This illustrates the differences that can be expected when freezing temperatures refer to different frozen fractions.

Classical nucleation theory predicts a dependence of nucleation rates (nucleation events per time) on the surface area present in a sample due to the stochastic nature of the nucleation process. Therefore, the freezing temperature is expected to increase with increasing surface area. An even stronger dependence of freezing temperature on surface area is expected when active sites are responsible for ice nucleation because the probability of containing an efficient active 
site increases with increasing surface area. This dependence is taken into account in Fig. 2 by plotting freezing temperatures as a function of surface area. For immersion freezing, the stochastic nature of nucleation also leads to a dependence of freezing temperatures on time. Vonnegut and Baldwin (1984) showed that the freezing temperature increased from 264 to $270 \mathrm{~K}$ when the observation time was extended from $1 \mathrm{~s}$ to $2 \mathrm{~h}$. For contact freezing, the number of collisions during the experiment has to be taken into account to convert frozen fractions to freezing efficiencies (e.g., Nagare et al., 2016). For this, the collision efficiency has to be known, a quantity that depends on many factors, such as the size and charge of particles and droplets, temperature and water vapor concentration gradients between droplet surface and the surroundings (see, e.g., Nagare et al., 2015). For adhesion freezing there is a dependence of freezing temperature on nucleation time, as for immersion freezing (Nagare et al., 2016). Since collisional contact freezing is supposed to be immediate when a particle collides with a droplet, the outcome of a comparison of the nucleation efficiencies of collisional contact freezing and immersion freezing depends on the timescale.

\subsection{Preparation method of AgI}

The preparation method of AgI influences the size, polymorphic form, morphology and number of surface defects of the produced particles. Most procedures lead to mixtures of the stable $\beta$ and the metastable $\gamma$ form (see Appendix B1). Commercial AgI is usually the $\beta$ form. The basal 001 and $00 \overline{1}$ faces of the $\beta$ form show a close lattice match with ice and are often considered responsible for the ice nucleation ability of AgI. These faces correspond to the $\overline{1} \overline{1} \overline{1}$ and 111 faces of the $\gamma$ form, respectively. Typical crystal habits of the $\gamma$ form expose these faces partly to the surface (see Appendix B2). Therefore, the condition of lattice match is realized also for the $\gamma$ form, so that this form can induce ice nucleation as well as the $\beta$ form if lattice match is important. This was confirmed in a recent molecular dynamics study by Zielke et al. (2015), who found that $\beta \mathrm{AgI}$ and $\gamma \mathrm{AgI}$ were able to nucleate ice but only on the silver exposed surface (see Appendix B4 for more details).

Edwards et al. (1962) prepared monodisperse silver iodide particles and noted that particles of the same size are not equally active, but behave as if the number of nucleation sites per particle is proportional to the surface area of the particle. This led them to the conclusion that ice nucleation does not occur on the whole surface but on surface irregularities, which may be preferred nucleation sites. They suggested that the occurrence of nucleation sites depends only on the surface area irrespective of whether there were a few large or many small particles in their sample. However, depending on the preparation method, AgI crystals may contain different amounts of surface irregularities. Shevkunov (2005) conjectured that particles produced by solution combustion and used for cloud seeding have a superior ice nucleation ability compared to crystals with perfect surfaces because, by this method, particles contain many surface defects. Nevertheless, from the immersion freezing studies compared in Fig. 2, such a relationship is not evident: freezing temperatures from experiments carried out with single crystals (Edwards et al., 1962) align well with freezing temperatures determined from emulsion experiments (Zobrist et al., 2008; Aguerd et al., 1982) conducted with irregularly shaped particles from precipitation (see Appendix A). Note that surface irregularities may be more important when the particles are exposed to air if the ice nucleation efficiency depends on the amount of water that adsorbs at surface defects or impurities (see discussion below).

When $\mathrm{AgI}$ is prepared by precipitation from $\mathrm{AgNO}_{3}$ and $\mathrm{KI}$ solutions, the counterions $\mathrm{K}^{+}$and $\mathrm{NO}_{3}^{-}$remain in solution and form conglomerates with $\mathrm{AgI}$ when the suspension is dried, e.g., during atomization (see Fig. A2 in Appendix A). $\mathrm{KNO}_{3}$ dissolves again when the particle is in contact with water. The freezing ability may be altered during dissolution. However, it is rather unlikely that an effect persists once the soluble salts are completely dissolved. The dilution of dissolved salts in the droplets is large enough so that the freezing point depression by the solute is negligible.

There is a strong influence of freezing temperatures on surface charge, which depends on the stoichiometric ratio of $\mathrm{Ag}^{+}$to I ${ }^{-}$ions. This charge effect has a strong influence on the ice nucleation ability of AgI particles and will be discussed below in Sect. 4.3.

\subsection{Lattice match and surface charge}

The closeness of fit between the ice lattice and the lattice of the ice-nucleating substance is often considered a basic requirement for heterogeneous ice nucleation. Indeed, AgI surfaces show a close lattice match with ice. The fit is even improved for $\mathrm{AgI}-\mathrm{AgCl}$ cubic solid solutions and the complex compound $3 \mathrm{AgI} \cdot \mathrm{NH}_{4} \mathrm{I} \cdot 6 \mathrm{H}_{2} \mathrm{O}$ (see Appendix B1). Davis et al. (1975) reported a misfit for the basal plane of $\beta \mathrm{AgI}$ with respect to the basal plane of ice of $1.5 \%$ at $266 \mathrm{~K}$ and an even smaller misfit of $1.3 \%$ with respect to the complex compound $3 \mathrm{AgI} \cdot \mathrm{NH}_{4} \mathrm{I} \cdot 6 \mathrm{H}_{2} \mathrm{O}$. This is consistent with the higher threshold freezing temperatures that they observed for $3 \mathrm{AgI} \cdot \mathrm{NH}_{4} \mathrm{I} \cdot 6 \mathrm{H}_{2} \mathrm{O}$ compared with AgI. Namely, heterogeneous ice nucleation on films of this compound occurred at $272 \mathrm{~K}$ for $3 \mathrm{AgI} \cdot \mathrm{NH}_{4} \mathrm{I} \cdot 6 \mathrm{H}_{2} \mathrm{O}$ compared with $269 \mathrm{~K}$ for AgI. Palanisamy et al. (1986a) determined ice nucleation threshold temperatures of bulk samples of $\mathrm{AgI}-\mathrm{AgCl}$ solid solutions with different $\mathrm{AgI}: \mathrm{AgCl}$ mixing ratios and compared them with lattice constants from X-ray powder diffraction. The $65: 35 \mathrm{~mol} \%$ combination of $\mathrm{AgI}$ and $\mathrm{AgCl}$ showed the best lattice match of $0.44 \%$ and the highest nucleation temperature of $271.97 \mathrm{~K}$ in bulk experiments. Experiments with AgI yielded a freezing temperature of $270.62 \mathrm{~K}$ and a lattice match of $1.77 \%$. $\mathrm{AgCl}$ has a large misfit of $12.86 \%$; never- 
theless, nucleation was observed at a threshold temperature of 269.13 K (Palanisamy et al., 1986a). A superior ice nucleation ability of $\mathrm{AgI}-\mathrm{AgCl}$ compared with $\mathrm{AgI}$ particles has also been observed by DeMott (1995) for experiments in the Colorado State University (CSU) isothermal cloud chamber.

While these studies support the importance of lattice match for the threshold freezing temperature, in other studies, the necessity and importance of lattice match is questioned. Conrad et al. (2005) explored homogeneous ice nucleation and found that the critical embryo that caused ice to form bears little structural similarities to hexagonal ice (Ih). Therefore, he suggested that the site for heterogeneous ice nucleation does not have to be ordered or, more particularly, does not have to possess a hexagonal geometry to match the structure of Ih. In a molecular dynamics study, Fitzner et al. (2015) found that lattice match is at most desirable but not a requirement for heterogeneous ice nucleation.

If there is an effect of a good lattice match, it can be annihilated by a high surface charge (see Appendix B3). A study by Edwards and Evans (1962) showed freezing temperatures that were highest for zero net charge and clearly lower in the presence of either excess $\mathrm{Ag}^{+}$or $\mathrm{I}^{-}$ions in the solution. Fletcher (1959) considered the importance of entropy for the growing ice embryo: a positive or a negative surface charge leads to a reduction in freezing efficiencies because the charge orders $\mathrm{OH}$ dipoles of water molecules parallel to one another and therefore reduces the entropy and raises the free energy of the growing ice embryo. The basal planes of $\mathrm{AgI}$ either end with $\mathrm{Ag}^{+}$or with $\mathrm{I}^{-}$ions. If ice grows on a basal face, the oxygens will be above ions which all have the same sign. Therefore, for lowest interfacial energy, the $\mathrm{OH}$ dipoles of the ice molecules at the interface must all be parallel leading in sum to low configurational entropy and to a high free energy of nucleation. The prism face exposes equal numbers of $\mathrm{Ag}^{+}$and $\mathrm{I}^{-}$on the surface. Therefore, there is no entropy effect on the prism face and Fletcher (1959) concluded that this face of silver iodide should be superior at nucleating ice compared with the basal face, although its lattice match is inferior, with a misfit of $1.6 \%$ compared to the value of $1.4 \%$ for the basal face (Fletcher, 1959). This conclusion was rejected by Fukuta and Paik (1973), who calculated potentials of water molecules adsorbed on AgI surfaces which indicated that the entropy effect of ice nucleation can be ignored on AgI surfaces because the maximum configurational entropy can be easily realized by the forming ice germ. In agreement with this, Fraux and Doye (2014) and Zielke et al. (2015) were able to simulate ice growth at the silver-terminated basal face of $\beta \mathrm{AgI}$ but neither on the iodide-terminated basal face nor on the prism face (see Appendix B4 for more details). The superiority of the $\mathrm{Ag}^{+}-$ terminated compared with the $\mathrm{I}^{-}$-terminated basal face was ascribed to the chair conformation of water molecules on the $\mathrm{Ag}^{+}$-terminated face, which resembles the chair conformation present in hexagonal and cubic ice (Zielke et al., 2015). Both studies found that ice did not grow directly on the substrate but that a templating mechanism may be active so that particular AgI surfaces impose a structure in the adjacent water layer that closely resembles a layer that exists in bulk ice (hexagonal or cubic). Ice nucleates on this layer and not directly on the AgI surface. Similarly, Taylor and Hale (1993) suggested that ice nucleation occurs within a thicker film of adsorbed water on the basal AgI face after the two-dimensional nucleation of a solid-like monolayer adjacent to the substrate. The three-dimensional nucleation would then occur on the ice-like underlayer with an extremely small lattice mismatch. However, such a templating mechanism does not rule out that defects, such as steps and ledges or impurities, are also important (Zielke et al., 2015; Taylor and Hale, 1993).

\subsection{Position of particles in or on the droplet}

Durant and Shaw (2005) and Shaw et al. (2005) showed that freezing temperatures for ice-nucleating particles that contact the water surface are higher than those of completely immersed particles. Depending on the experimental setup, particles can be forced into a position either in or on the droplet or they can be free to take the energetically most favorable position. In the studies performed by Edwards et al. (1962) and Edwards and Evans $(1962,1968)$ particles stick to the substrate and are completely immersed in the droplets. In the emulsion freezing studies by Zobrist et al. (2008) and Aguerd et al. (1982) droplets are within the oil phase so that the particles within the droplets have no access to the air-water interface.

If particles are floating in a droplet or bulk volume with free access to the air-water interface, the position of the particles depends on their wetting behavior with water. In the absence of other forces, they become completely immersed when they are completely wetted by water (contact angle of 0 ), otherwise they float on the surface (Nagare et al., 2016). For AgI the (intermediate advancing) contact angle is 45$50^{\circ}$ (see Appendix B5), indicating that particles adhere to the water surface. This is in accordance with our own observations that $\mathrm{AgI}$ particles remain on the surface when gently sprinkled on water (Nagare et al., 2016) and with the observations by Gokhale and Goold (1968) and Gokhale and Lewinter (1971) when they sprinkled AgI particles on drops.

When an ice-nucleating particle is activated to a cloud droplet, it is usually considered to be completely immersed in the droplet. However, when an AgI particle is free to take the energetically most favorable position, it will adhere to the surface of a droplet. The analysis of immersion freezing studies in Fig. 2 suggests that freezing temperatures are higher for those studies where the particle is free to take a position on the surface of the droplet, as is the case for experiments performed with IMCA-ZINC or with a cloud chamber, as in the study by Sax and Goldsmith (1972).

During contact freezing experiments carried out in the CLINCH chamber, particles should remain on the surface 
of the droplets after collision. For immersion freezing experiments in IMCA-ZINC and contact freezing experiments in CLINCH, the same AgI preparation procedure was used, the same particle sizes were selected and residence times in the chambers were comparable. Therefore, similar freezing temperatures could be expected in both experiments. However, median freezing temperatures were around $16 \mathrm{~K}$ lower for contact freezing experiments in the CLINCH chamber than for immersion freezing experiments in the IMCA-ZINC chamber. Possible explanations for this will be discussed in the sections below.

\subsection{Water adsorption and surface irregularities}

The reason why freezing temperatures are increased when the ice-nucleating particle is positioned at the air-water interface compared with being completely immersed is still debated. Gokhale and Lewinter (1971) conjectured that particles on the surface are better at nucleating ice than completely immersed particles because of two likely reasons: first, water molecules probably have less freedom of movement on the surface than molecules within the drop since they are more or less bound into a polarized layer at the surface. An oriented layer of this nature should be more susceptible to nucleation than disoriented bulk water. Second, the dissipation of latent heat is much easier at the surface than within the bulk water. Another explanation that has gained increasing attention recently, is that the energy barrier is reduced at the three-phase contact line of water, air and nucleating surface (Djikaev and Ruckenstein, 2008; Gurganus et al., 2014).

How much water is adsorbed on the AgI surface depends on the relative humidity and the presence of surface irregularities. The water uptake of a defect-free AgI surface was calculated to be below one nominal monolayer at water saturation. Even above water saturation, water gathers in patches and does not form a monolayer also at nominal monolayer coverage (see Appendix B4). More water can adsorb on a surface with irregularities, such as defects and impurities, compared with a perfect surface. In this case, water patches form in and around these irregularities and may be the starting point for ice nucleation.

If ice nucleation did indeed occur on such water patches on the AgI surface, ice nucleation efficiency should depend on RH. Contact freezing experiments in CLINCH were performed at ice saturation and immersion freezing experiments in IMCA-ZINC at water saturation. Therefore, more water is adsorbed on the AgI surfaces in IMCA-ZINC experiments, which may indeed increase the freezing temperature (for water adsorption on AgI surfaces, see Appendix B4). Condensation freezing studies showed that the highest freezing temperatures are obtained for high supersaturation during activation (Schaller and Fukuta, 1979; Zimmermann et al., 2007), which may increase the amount of water present at the surface of the particle. There is evidence that ice crystals form on specific sites (Bryant et al., 1959). These sites may be surface irregularities like dislocations and steps where water uptake is enhanced. Bryant et al. (1959) observed that at $T=261-269 \mathrm{~K}$ ice crystals formed at selected sites when the air was supersaturated with respect to water. At lower temperatures it was sufficient when the air was supersaturated with respect to ice. Bassett et al. (1970) conjectured that ice nucleation is proceeded by water adsorption at discrete locations, which may be polar impurities on a hydrophobic surface leading to cluster formation and rapid migration of weakly adsorbed molecules to the growing clusters. Freezing of some of the clusters should occur before the surface of the substrate is completely covered by a liquid-like layer of water. When the substrate also exhibits good fit with ice, as in the case of silver iodide, the interfacial energy is reduced and the nucleating ability should be maximized. Thus, a disordered cluster of adsorbed water molecules may not offer as much resistance to freezing as bulk water. Once formed, growth of the ice island is facilitated by rapid diffusion of molecules weakly adsorbed on the rest of the surface (Bassett et al., 1970).

\subsection{Solubility and dissolution of AgI}

Silver iodide is a sparingly soluble salt with a solubility product of around $10^{-16}$ at $298 \mathrm{~K}$ (Hiemstra, 2012). The solubility decreases with decreasing temperature and reaches a value $<10^{-17}$ at $273 \mathrm{~K}$ (Lyklema, 1966). Nevertheless, a small particle in a large droplet will dissolve to some degree. In the CLINCH chamber (Nagare et al., 2015, 2016), a $200 \mathrm{~nm}$ particle will dissolve by around $2.4 \%$ when it collides with an $80 \mu \mathrm{m}$ droplet. In the IMCA-ZINC setup, particles with diameters between 20 and $200 \mathrm{~nm}$ were activated to droplets of $20 \mu \mathrm{m}$, leading to partial dissolution of $0.04 \%$ for a $200 \mathrm{~nm}$ particle and $38 \%$ for a $20 \mathrm{~nm}$ particle. Effective dissolution may even be larger because the particles prepared by precipitation also contain shares of $\mathrm{KNO}_{3}$ (see Appendix A).

Partial dissolution of a particle changes its shape and surface. Steps, corners and kinks of atomic dimensions are eroded away and pits below a critical size form and disappear spontaneously. If they have reached the critical size, they continue to grow (Conrad et al., 2005). Pits are preferentially generated along or in dislocation boundaries. Calculations by Conrad et al. (2005) demonstrated that pitting improved the ice nucleation ability of $\mathrm{a} \mathrm{BaF}_{2}$ surface.

During the dissolution process, nucleation may be impeded because the eroding surface is changing too fast to let an ice embryo grow. Moreover, dissolution may lead to (additional) surface charge (Waychunas, 2014). A transient charge during dissolution may result when $\mathrm{Ag}^{+}$and $\mathrm{I}^{-}$ions dissolve at different rates. Klimeš et al. (2013) have recently shown a preference for the dissolution of $\mathrm{Cl}^{-}$ions over $\mathrm{Na}^{+}$ions in dissolving $\mathrm{NaCl}$ crystals. The $\mathrm{Cl}^{-}$ions are released first as this exposes more $\mathrm{Na}^{+}$ions at the surface creating favorable adsorption sites for water. A similar effect may also influ- 
ence the charge on dissolving AgI surfaces because of the better solubility of $\mathrm{Ag}^{+}$compared to the one of $\mathrm{I}^{-}$(Hiemstra, 2012). However, precise predictions are not possible because aqueous dissolution processes are not well understood on the molecular scale yet (Waychunas, 2014).

The timescale of dissolution can be calculated with the Noyes-Whitney equation (see Appendix B6). Using this equation, particles that collide with droplets in CLINCH will keep dissolving during the residence time of 2 and $4 \mathrm{~s}$ in the chamber. On the other hand, droplets activated in the IMCAZINC instrument probably reach saturation while still in the IMCA section so that there is no ongoing dissolution in the ZINC chamber where ice nucleation should occur. If nucleation is indeed impeded on dissolving crystals, this difference may explain the superior ice nucleation ability of $\mathrm{AgI}$ particles in IMCA-ZINC compared with CLINCH. If in contact freezing experiments more than one particle collides with a droplet, dissolution will be strongest for the first particle and less for subsequent ones. Indeed, for the highest particle concentration of $5000 \mathrm{~cm}^{-3}$ in CLINCH, more than two particles collided on average with a droplet. This may explain the higher freezing temperature for this concentration compared with lower ones.

If ice nucleation on dissolving AgI particles is reduced, the experiments performed by Sax and Goldsmith (1972) should also be affected by dissolution because in these experiments the residence time in the chamber was on the same timescale as dissolution (about $4 \mathrm{~s}$ ).

\subsection{Weather modification by cloud seeding}

The era of weather modification started in the 1940s with first field experiments with the intention of stimulating rain from convective clouds by glaciogenic seeding (Silverman, 2001). Since then many operational programs and scientific studies have been conducted for rain enhancement and hail suppression (Chen and Xiao, 2010; Breed et al., 2014). In these programs silver iodide smoke is produced and injected into clouds, mostly with ground-based methods, but also with airplanes or rockets. Although in many countries weather modification programs are conducted, considerable skepticism exists as to whether these methods indeed provide a cost-effective means for increasing precipitation for water resources (Bruintjes, 1999). The ability to influence and modify cloud microstructure in certain simple cloud systems such as fog and simple orographic clouds has been demonstrated in observational studies (Bruintjes, 1999). Nevertheless, the general impact of glaciogenic seeding is still uncertain since it is a challenge to detect a signal from seeding in the noisy pattern of precipitation (Pokharel et al., 2014). Cloud seeding strategies have been established for seeding of cold clouds. There is a need to adapt and optimize seeding strategies according to the different situations based on laboratory findings and numerical models (Garstang et al., 2005). Focusing on the microphysical aspects of cloud seeding, it is required to improve the understanding of how seeding agents form ice.

Most AgI aerosols used operationally for weather modification are produced by solution combustion or pyrotechnic generation methods (DeMott, 1995). Atomized AgI-acetone solutions are burned in a propane flame. During subsequent cooling in the atmosphere, aerosol particles form. Usually, instead of pure $\mathrm{AgI}$, a mixture of $\mathrm{AgI}$ and $\mathrm{AgCl}$ is used to produce $\mathrm{AgI}-\mathrm{AgCl}$ solid solutions with an improved ice nucleation ability compared with AgI (probably due to a better lattice match; see also Sect. 4.3). Large laboratory cloud chambers have been used to determine the ice nucleation effectiveness of aerosols for weather modifications (DeMott et al., 1983). The optimal sublimation temperature for silver iodide was found to be $1023 \mathrm{~K}$. The optimal suspension concentration in acetone was determined to be $2 \mathrm{wt} \%$ (Shevkunov, 2005).

Combustion produces particles with diameters of around $30 \mathrm{~nm}$, with only few particles reaching sizes of $100 \mathrm{~nm}$. It is unlikely that these small particles act as $\mathrm{CCN}$ because the Kelvin effect opposes the activation to droplets. To enhance the water uptake of silver iodide particles, $\mathrm{NaCl}$ is often added to the acetone solution to increase the hygroscopicity of the particles and to improve their ability to act as $\mathrm{CCN}$. When such particles freeze during $\mathrm{CCN}$ activation, this is considered to be ice nucleation in condensation mode. Cloud droplet formation followed by further cooling before ice nucleation would be attributed to immersion or adhesion freezing. If clouds are seeded from an airplane, the relative humidity is often too low for new CCN activation and the silver iodide particles need to collide with existing cloud droplets to act as ice-nucleating particle. Collisions of such small particles with cloud droplets occur mainly by Brownian diffusion (Seinfeld and Pandis, 2006). If the droplets bear high charges, the attraction by electrostatic forces may increase the number of collision between silver iodide particles and cloud droplets. The analysis presented in this study suggests that the ice nucleation ability of dissolving AgI particles is reduced. Moreover, the freezing temperature increases with increasing surface area. Therefore, high enough concentrations to saturate cloud droplets with $\mathrm{AgI}$ are needed for glaciogenic seeding in the case of low supercooling.

\section{Conclusions}

Ice nucleation by silver iodide has been the subject of many experimental and theoretical studies. Although it is an artificial ice nucleus, it has relevance for the atmosphere since it is used for glaciogenic cloud seeding. In this review, physical properties of AgI have been analyzed with special attention to the ones that may be important for heterogeneous ice nucleation. Freezing temperatures as a function of surface area of AgI have been evaluated. The following factors seem to be relevant for heterogeneous ice nucleation on AgI particles: 
- The ice nucleation ability of AgI seems to be enhanced when the AgI particle is on the surface of a droplet compared with completely immersed. This is indeed the position that an AgI particle takes when it can move freely in a droplet.

- For AgI particles partly exposed to air, the ice nucleation ability seems to be influenced by surface water. Water adsorption increases with increasing relative humidity and is enhanced in the presence of surface defects. Indeed, some of the highest freezing temperatures have been observed for condensation freezing when cloud droplet activation occurred at high supersaturation with respect to water.

- For AgI particles that are completely immersed in water, the freezing temperature increases with increasing $\mathrm{AgI}$ surface area. There is no evident influence of the number of surface defects. Surface defects may be more important when water adsorption on particles exposed to air is involved in ice nucleation.

- Higher threshold freezing temperatures seem to correlate with improved lattice match. $\mathrm{AgI}-\mathrm{AgCl}$ solid solutions and $3 \mathrm{AgI} \cdot \mathrm{NH}_{4} \mathrm{I} \cdot 6 \mathrm{H}_{2} \mathrm{O}$ have slightly better lattice matches with ice than AgI, and their threshold freezing temperatures are also slightly higher.

- Edwards and Evans (1962) showed a clear dependence of ice nucleation ability on surface charge with highest freezing temperatures close to the point of zero charge and lower ones for positively and negatively charged surfaces.
- No influence of the polymorphic form on the ice nucleation ability of AgI could be detected. Most preparation methods yield mixtures of the stable $\beta$ and the metastable $\gamma$ form in different proportions. No correlation becomes evident when the prevailing form expected for a given preparation procedure is compared with freezing temperature. This is in accordance with the results of recent modeling studies that surfaces of the $\beta$ and the $\gamma$ form are able to nucleate ice (Zielke et al., 2015).

- The ice nucleation ability may be decreased while AgI particles are dissolving. AgI is a sparingly soluble salt. If only one particle is present in a large cloud droplet, dissolution is nevertheless relevant. During dissolution, particles may acquire surface charge, which reduces the ice nucleation ability. The dissolution of nanoscale droplets should occur on the timescale of seconds to minutes. When saturation solubility is reached dissolution levels off and nanoscale pits acquired during dissolution may be preferred nucleation sites. This introduces an additional history and time dependence of ice nucleation in cloud chambers with short residence times.

\section{Data availability}

To get access to the data please contact Claudia Marcolli (claudia.marcolli@env.ethz.ch) or André Welti (welti@tropos.de). 
Appendix A: Characterization of AgI particles prepared by precipitation

In the CLINCH and IMCA-ZINC studies, aerosol particles were produced by atomizing a suspension of $\mathrm{AgI}$ particles prepared by precipitation from $\mathrm{KI}$ and $\mathrm{AgNO}_{3}$ solutions. To decrease the concentration of dissolved $\mathrm{KNO}_{3}$, the supernatant solution was removed and replaced by water as described in Nagare et al. (2015). The suspensions were used for ice nucleation experiments for the next few days. X-ray diffraction of the dried precipitate revealed that it consists of a mixture of the $\beta$ phase and $\gamma$ phase in similar proportions that transformed completely into the $\beta$ phase within less than 1 week when kept in suspension. A scanning mobility particle sizer (SMPS) system (TSI 3936 using a DMA 3081) was used to measure the particle size distribution, which could be fitted with a lognormal distribution with median diameter of about $70 \mathrm{~nm}$ (Fig. A1). Transmission electron microscopy (TEM) and high-angle annular dark field (HAADF) scanning transmission electron microscopy (STEM) showed a predominance of particles in the 100 to $500 \mathrm{~nm}$ diameter size range but additionally also the presence of particles with diameters down to $20 \mathrm{~nm}$. The electron microscopy images together with energy-dispersive X-ray spectroscopy (EDX) of selected particles shown in Fig. A2 reveal that the particles are conglomerates of $\mathrm{AgI}$ and $\mathrm{KNO}_{3}$ crystallites. The primary particles exhibit sizes with diameters ranging from about 20 to $300 \mathrm{~nm}$. When conglomerated particles become immersed in a droplet, $\mathrm{KNO}_{3}$ will dissolve and the primary particles may be released or a conglomerate of AgI may persist.

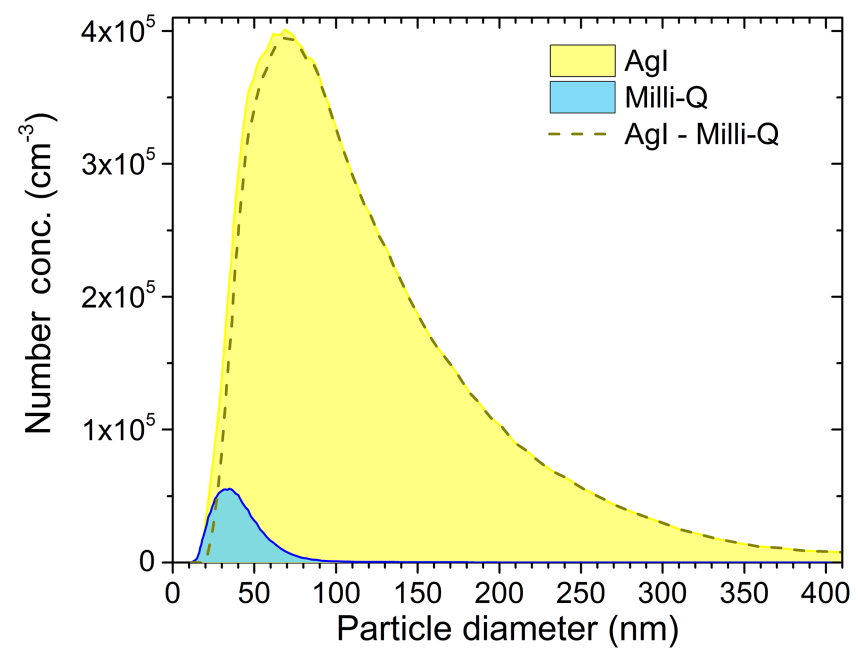

Figure A1. Size distribution of an AgI suspension in Milli-Q water (yellow area) measured with a scanning mobility particle sizer (SMPS) system (TSI 3936 using a DMA 3081). Pure Milli-Q water measured with the same method and settings is shown as the blue area. The difference curve area(AgI) - area(Milli-Q) is given as dashed line.

\section{Appendix B:}

\section{B1 Polymorphic forms}

Silver iodide exists in three polymorphic forms. The $\alpha$ modification represents a body-centered cubic (bcc) lattice. It is the stable form at temperatures above $420 \mathrm{~K}$ and melts when heated to $828 \mathrm{~K}$ (Burley, 1963). The hexagonal $\beta \mathrm{AgI}$ is of wurtzite-type and shows a hexagonal closest packing of iodine atoms (Cava and Rietman, 1984). It is thermodynamically stable under ambient pressure and temperature and transforms to the high-temperature stable $\alpha$ modification at $420 \mathrm{~K}$. The $\gamma$ modification represents a face-centered cubic lattice (fcc) with a zinc-blende-type crystal structure. It is presumably metastable at all temperatures but can be preserved as powder at room temperature for days. It transforms to the hexagonal form within hours when the temperature is kept between 373 and $420 \mathrm{~K}$ and to the high-temperature stable $\alpha$ form at $T>420 \mathrm{~K}$ (Berry, 1967).

In a stoichiometric ratio, silver iodide $\mathrm{Ag}^{+}$and $\mathrm{I}^{-}$ions both have four nearest neighbors. The bonding is partly covalent. The structure can be described as two interpenetrating hexagonally close-packed sublattices, to either give the characteristic $(\mathrm{AB})$ stacking sequence of the hexagonal $\beta \mathrm{AgI}$ or the cubic stacking sequence $(\mathrm{ABC})$ of the zinc-blendestructured $\gamma$ AgI (Morgan and Madden, 2011). Both the hexagonal and low-cubic phases show a closest packing of iodine atoms with tetrahedral and octahedral holes. Half of the tetrahedral sites but no octahedral sites are occupied by silver. Whether $\beta \mathrm{AgI}$ or $\gamma \mathrm{AgI}$ is realized can be influenced by other cations present as impurities or small shares. Excess cations will enter available interstitial sites, either tetrahedral or octahedral, depending on the ionic radius (Burley, 1963). An excess of cations at the tetrahedral sites should stabilize the hexagonal phase, while an excess at the octahedral sites should stabilize the low-cubic phase. Cations with radii between 0.53 and $0.97 \AA$, such as $\mathrm{Fe}^{2+}, \mathrm{Li}^{+}, \mathrm{Cu}^{2+}$ and $\mathrm{Na}^{+}$, are able to occupy tetrahedral sites; cations with radii between 0.97 and $1.71 \AA$, such as $\mathrm{K}^{+}, \mathrm{Ba}^{2+}, \mathrm{NH}_{4}^{+}$and $\mathrm{Cs}^{+}$, may occupy octahedral sites (Burley, 1963).

Coprecipitation of AgI with other silver halides yields solid solutions in which part of the iodide is substituted by the other halide ion. Coprecipitation with $\mathrm{AgBr}$ and $\mathrm{AgCl}$ leads to a contraction of the AgI lattice due to the smaller ionic radii of $\mathrm{Br}^{-}$and $\mathrm{Cl}^{-}$ions compared with $\mathrm{I}^{-}$(Vonnegut and Chessin, 1971; Palanisamy et al., 1986a, b). X-ray powder diffraction of $\mathrm{AgI}-\mathrm{AgCl}$ solid solutions has shown that even small impurities with $\mathrm{AgCl}$ lead to cubic solid solutions (Palanisamy et al., 1986a). In the presence of ammonium, the complex compound $3 \mathrm{AgI} \cdot \mathrm{NH}_{4} \mathrm{I} \cdot 6 \mathrm{H}_{2} \mathrm{O}$ may form, which has a better epitaxial fit with respect to ice than has silver iodide. The unit cell of this phase is monoclinic, and its stability range includes the temperature range from 253 to $282 \mathrm{~K}$ at water saturation (Davis et al., 1975). 

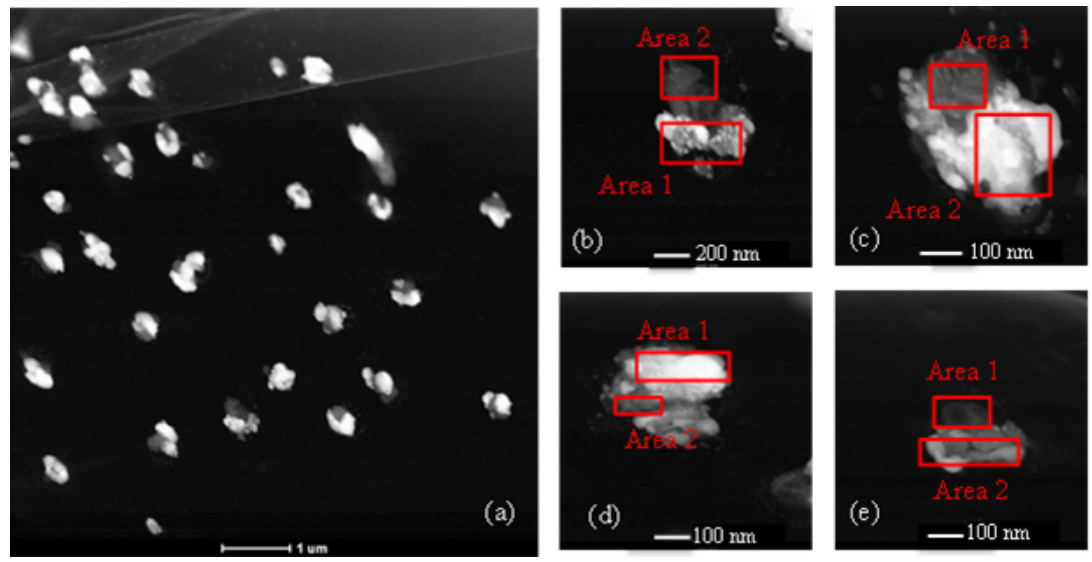

Figure A2. High-angle annular dark field (HAADF) scanning transmission electron microscopy (STEM) of AgI particles formed by precipitation. Panel (a) shows an overview and panels (b-e) individual particles for which EDX (energy-dispersive X-ray) spectroscopy has been performed. Panel (b): in area 1 silver and iodine were detected with small amounts of oxygen and potassium; in area 2 potassium and chloride were detected. Panel (c): in area 1 silver and iodine was detected; for area 2 the EDX spectrum showed a large peak for potassium and small peaks for chlorine and oxygen. Panel (d): area 1 contained mainly silver and iodine, area 2 silver and iodine and possibly small amounts of potassium. Panel (e): the EDX spectrum of area 1 showed a small peak for potassium and small amounts of silver and iodine, area 2 silver and iodine.

The commercial powder (Sigma-Aldrich) is of the hexagonal $\beta$ form (Guo et al., 2006). By applying pressure by grinding, the powder transforms partly to the $\gamma$ modification (Burley, 1963). Precipitation of $\mathrm{AgNO}_{3}$ and $\mathrm{KI}$ in a stoichiometric ratio at room temperature usually leads to mixtures of the $\beta$ and $\gamma$ modification (Burley, 1963; Berry, 1967). Manson (1955), for example, reports $36 \pm 8 \%$ of the $\beta$ phase in the precipitate. The only conditions of precipitation which produced entirely hexagonal crystals were when gelatin was present and the solutions were added slowly without an excess of either $\mathrm{Ag}^{+}$or $\mathrm{I}^{-}$(Berry, 1967). Faster precipitations give mixtures of the cubic and hexagonal phases, and crystals whose average diameter was as small as $15 \mathrm{~nm}$ (Berry, 1967). $\beta \mathrm{AgI}$ is preferentially produced in the presence of an excess of iodide ions. In the presence of excess silver ions, $\gamma \mathrm{AgI}$ is the predominant form (Sidebottom et al., 1976; Burley, 1963). If the precipitate is kept in solution, the $\gamma$ modification transforms to the stable $\beta$ form. Quenching AgI that has been heated to $823 \mathrm{~K}$ in air or water primarily produces the metastable $\gamma$ form, while slow cooling results in stable $\beta$ AgI (Burley, 1963). When AgI is formed by the condensation of silver and iodine vapors from the gas phase, $73 \pm 2 \%$ of the $\beta$ phase forms when the vapors are heated to $923 \mathrm{~K}$ and even the $95 \pm 2 \%$ of the $\beta$ phase is obtained when the vapors are heated to $1073 \mathrm{~K}$ or higher (Manson, 1955). This can be explained by excess iodine present during crystallization: since silver has a very low vapor pressure even at $1273 \mathrm{~K}$, it will condense within the source tube to a large extent, whereas iodine, which boils at $456 \mathrm{~K}$, will be carried out in the effluent and be present in excess. Silver iodide with high shares of $\gamma \mathrm{AgI}$ can also be obtained by lengthy grinding with a mortar and pestle or by the application of hydrostatic pres- sure. Complete conversion to the low-cubic form appears to be impossible (Burley, 1963). Tomaev et al. (2012) reports that the mechanical modification of $\beta$ AgI nanocrystals of $500-1000 \mathrm{~nm}$ in size stimulates the faceting of the crystals without a significant change in their size and the formation of smaller $\beta$ AgI crystals with a characteristic size of $40 \mathrm{~nm}$ on their surface. Precipitation of $\mathrm{AgI}$ from $\mathrm{KI}$ and $\mathrm{AgNO}_{3}$ with the experimental procedure of Nagare et al. (2015) led to a mixture of $\beta \mathrm{AgI}$ and $\gamma \mathrm{AgI}$ that also contained $\mathrm{KNO}_{3}$ (see Appendix A). The $\gamma$ modification transformed to the $\beta$ modification within days, as was determined by $\mathrm{X}$-ray diffraction.

\section{B2 Crystal faces and morphology}

A cut along the basal plane of $\beta$ AgI creates the $\overline{1}$ face with triply coordinated $\mathrm{I}^{-}$ions and the corresponding 001 face with triply coordinated $\mathrm{Ag}^{+}$ions. Following the definitions of Hiemstra (2012), the 111 face of $\gamma$ AgI terminates with $\mathrm{I}^{-}$ ions and has the same structure as the $00 \overline{1}$ face of $\beta$ AgI. The $\overline{1} 1 \overline{1}$ face terminates with $\mathrm{Ag}^{+}$ions and has the same structure as the 001 face of $\beta$ AgI. The fully loaded $111 / \overline{1} 1 \overline{1}$ face of $\gamma$ AgI can perfectly match the fully loaded $001 / 00 \overline{1}$ face of $\beta$ AgI. Both faces have the same site density and basic structure, enabling the twinning of the two crystal types. Neutral surfaces can be created by the removal of triply coordinated ions from the lattice. With the sites and site densities of these faces, it is not possible to describe the asymmetric charging of AgI crystals, suggesting that they do not contribute significantly to the variable charge behavior of silver iodide. When $\beta \mathrm{AgI}$ is fractured in parallel to the lateral faces of the periodicity cell exposing the 100 face, ions of both signs are present on the fracture surface. In contrast to the fracture along the bases, there will be no features of hexagonal symmetry on the 
fracture surface, and the electric field of ions is less uniform (Shevkunov, 2005). The surface of the 100 face of $\beta \mathrm{AgI}$ is neutral because $\mathrm{Ag}^{+}$and $\mathrm{I}^{-}$are present in equal amounts, but it can attain a positive charge by adsorbing $\mathrm{Ag}^{+}$ions, which will protrude from the surface (Hiemstra, 2012). The same is valid for the 110 face of $\gamma \mathrm{AgI}$ because it is structurally the same. Applying surface complexation modeling to the 100 face, Hiemstra (2012) came to the conclusion that negative charge is created by desorption of $\mathrm{Ag}^{+}$from the surface leading to positive charge above the surface and negative charge on the surface; thus, a charge separation is introduced.

Single crystals of $\beta \mathrm{AgI}$ form hexagonal plates or prisms with 100 faces at the edge (lateral face) and 001/001 faces on the planar side (basal face) (Hiemstra, 2012). Depending on growth conditions, they can also form triangular plates (Burley, 1963). In the presence of hexagonal steps, hexagonal pyramids may presumably form by a screw mechanism (Burley, 1963). Crystals of $\gamma \mathrm{AgI}$ may form tetrahedrons terminated by the 111 face or dodecahedrons with dominant 110 faces beside a contribution of 111 faces (Hiemstra, 2012). Octahedra indicate $\gamma$ AgI (Sidebottom et al., 1976). Moreover, the twinning of $\beta \mathrm{AgI}$ and $\gamma \mathrm{AgI}$ is possible because of the same surface structure of the planar $(00 \overline{1} / 001)$ face of $\beta$ $\mathrm{AgI}$ and the 111/ $\overline{1} \overline{1} \overline{1}$ face of $\gamma \mathrm{AgI}$, as can be observed for large crystals (Hiemstra, 2012). The dominant 110 face of $\gamma$ $\mathrm{AgI}$ has the same type of structure as the edge (100) face of $\beta$ AgI (Hiemstra, 2012). When $\gamma$ AgI particles approach spherical morphology, the 110 face and its equivalents are dominant and the 111-type faces are minor. In the case of equal distances for the opposing crystal faces, the calculated contribution of the 110-type faces is $74 \%$. For hexagonal crystals of $\beta \mathrm{AgI}$, the contribution of the dominant edge faces is $67 \%$ at equal distances for all opposing surfaces (Hiemstra, 2012).

\section{B3 Surface charge in water and aqueous solutions}

Because of the better solubility of $\mathrm{Ag}^{+}$compared to $\mathrm{I}^{-}$, a neutral AgI crystal will be negatively charged in water or aqueous solutions. The negative particle charge can be diminished by the addition of extra $\mathrm{Ag}^{+}$ions, which may readsorb depending on the solution concentration. Adsorption of $\mathrm{Ag}^{+}$ions leading to positive charge above the surface and negative charge on the surface induces an electrical double layer consisting of an inner and an outer (second) Stern layer. At a certain $\mathrm{Ag}^{+}$concentration, equal numbers of $\mathrm{Ag}^{+}$and $\mathrm{I}^{-}$are present at the particle surface. Under this solution condition, the particle is in its point of zero excess adsorption or point of zero charge (PZC) (Hiemstra, 2012). The PZC describes the charge of the inner layer (first Stern layer). The charge of the outer layer (second Stern layer) is in addition influenced by the presence of $\mathrm{OH}^{-}$and $\mathrm{H}_{3} \mathrm{O}^{+}$ions and therefore depends on $\mathrm{pH}$. The origin of the charge of interfacial water is usually attributed to the higher affinity of $\mathrm{OH}^{-}$ions, with respect to $\mathrm{H}^{+}$ions, for the accumula- tion at the interface (Kallay et al., 2012). At high pH the diffuse double layer is negatively charged and at low $\mathrm{pH}$ it is positively charged. Zero charge is reached at the isoelectric point (IEP). The PZC depends only on the concentrations of $\mathrm{Ag}^{+}$or $\mathrm{I}^{-}$ions ( $\mathrm{pAg}$ or $\mathrm{pI}$ with $\mathrm{pAg}+\mathrm{pI}$ yielding the solubility product of $\mathrm{AgI}$ ) because the $\mathrm{Ag}^{+}$and $\mathrm{I}^{-}$ions are charge-determining, whereas the proton is indifferent. Lyklema and Golub (2007) determined the PZC by the titration of an $\mathrm{AgI}$ suspension which they had kept for 2 months in a solution with $\mathrm{pI}=4$. They obtained $\mathrm{PZC}=5.8$ (instead of 5.6 which is mostly cited in literature) and did not find a dependence on solution pH. Kallay et al. (2012) measured the IEP, which is also influenced by the charge present due to absorbed $\mathrm{OH}^{-}$and $\mathrm{H}_{3} \mathrm{O}^{+}$ions in the second Stern layer. They precipitated AgI particles by gradually adding a KI solution to a silver nitrate solution until the equivalence point was reached and the particles settled. The precipitated particles were washed and dried. They determined the IEP by adding the AgI powder in portions to a diluted potassium iodide solution at $\mathrm{pH} 6$, yielding 4.1 for $\mathrm{KNO}_{3}$ concentrations of $10^{-2}-10^{-3} \mathrm{~mol} \mathrm{~L}^{-1}$, and at $\mathrm{pH} 3$, giving $4.6\left(10^{-2} \mathrm{~mol} \mathrm{~L}^{-1}\right.$ $\left.\mathrm{KNO}_{3}\right)$ and $4.8\left(10^{-3} \mathrm{~mol} \mathrm{~L}^{-1} \mathrm{KNO}_{3}\right)$. These results support the hypothesis that in a neutral environment around $\mathrm{pH}=7$, the negative charge of water layers at silver iodide surfaces significantly contributes to the electrokinetic charge of the particles but does not significantly affect the (inner) surface potential. Hiemstra (2012) applied advanced surface complexation modeling (SCM) to the AgI surface and concluded that the inner Stern layer has a very low capacitance in accordance with a strong orientation of primary hydration water in the local electrostatic field of the $\mathrm{Ag}^{+}$and $\mathrm{I}^{-}$ions. Due to the high water ordering at the AgI surface, the secondary hydration water in the outer Stern layer is also rather strongly structured (Hiemstra, 2012). It is more difficult to charge the AgI surface positively by $\mathrm{Ag}^{+}$adsorption than to render it negative by uptake of $\mathrm{I}^{-}$ions (Bijsterbosch and Lyklema, 1978). The $\mathrm{Ag}^{+}$activity at the PZC always exceeds the corresponding $\mathrm{I}^{-}$concentration by many decades. $\mathrm{Ag}^{+}$ions show a stronger tendency to bind $\mathrm{NO}_{3}^{-}$ions than adsorbed $\mathrm{I}^{-}$ ions to bind cations.

\section{B4 Water adsorption and ice nucleation}

In the 1960s, adsorption isotherms of water on $\mathrm{AgI}$ were measured by several groups and compared with the adsorption of inert gases $\left(\mathrm{N}_{2}, \mathrm{Kr}\right.$ and $\left.\mathrm{Ar}\right)$ by applying the BET (Brunauer-Emmett-Teller) relation. Studies were performed for different preparation methods and degrees of sample purity and at several temperatures. Tcheurekdjian et al. (1964) measured adsorption isotherms at $T=259-293 \mathrm{~K}$ of $\mathrm{AgI}$ samples obtained by sublimation, by precipitation, for a sample treated with ammonia and also for a commercial sample. They observed that water coverage is only one quarter of the argon area at the nominal monolayer value. Based on this, they concluded that the surface of AgI is largely hydropho- 
bic possessing isolated hydrophilic sites. The entropy of the adsorbed molecules is high, indicating considerable lateral movement. The measurements performed by Hall and Tompkins (1962) at $T=228-248 \mathrm{~K}$ confirmed the hydrophobic nature of the AgI surface. Corrin and Nelson (1968) investigated water adsorption for $T=257-270 \mathrm{~K}$ of AgI prepared by silver and iodine reacted in vacuo and purified in liquid ammonia solution. Applying the evaluation procedure suggested in Tcheurekdjian et al. (1964) to this sample resulted in a hydrophilic character of $6-9 \%$. The maximum in isosteric heats was reached for coverages below one monolayer, which was interpreted as a "pseudomonolayer" effect corresponding to cooperative adsorption in patches. Corrin et al. (1964) investigated water adsorption at $303 \mathrm{~K}$ on an $\mathrm{AgI}$ sample prepared by the reaction between metallic silver and iodine and subsequent treatment with liquid ammonia and a material prepared by precipitation. They concluded that it is quite unlikely that a statistical monolayer of water exists on the surface of AgI at relative pressures less than unity. Higher values are probably due to small amounts of hygroscopic impurities on the AgI surface. Barchet and Corrin (1972) measured adsorption isotherms of a fine powder of AgI that should be free of hygroscopic ionic impurities but with particles containing numerous surface dislocations. The shape of the isosteric heat curves indicated that the adsorbed water was distributed in patches on the surface. Water vapor adsorption isotherms at $270.15 \mathrm{~K}$ showed a rapid increase in adsorption when the water vapor pressure rose above ice saturation but remained finite even at water saturation. The isotherms recorded at 266.65 and 263.15 were terminated by nucleation of the ice phase. Because the surface excess at nucleation clearly increased with temperature, Barchet and Corrin (1972) concluded that the number of embryos which formed on the water-adsorbing sites as well as the number of sites did not increase with temperature but that the embryos themselves were larger at higher temperatures.

Barnes (1963) analyzed the NMR (nuclear magnetic resonance) signal of the protons of water molecules on an AgI powder saturated with water vapor to investigate water adsorption and ice nucleation. He found no hysteresis between increasing and decreasing temperature and therefore suggested that all the water present is adsorbed on the surface and not as capillary condensate in pores or pore-like spaces. Moreover, all the adsorbed water layers seemed to be able to freeze at the same temperatures. Using proton spin resonance spectroscopy, Barnes and Sänger (1961) established that the adsorbed water on silver iodide transforms from a liquid-like state to solid-like state in a temperature range of $20 \mathrm{~K}$ with an onset of ordering close to the threshold temperature of heterogeneous ice nucleation on silver iodide.

Taylor and Hale (1993) simulated two water layers adsorbed on a model silver iodide (iodine exposed) basal face from 150 to $425 \mathrm{~K}$ using Monte Carlo methods. They observed a complex temperature dependence of the structure of the two-layer water condensate where quasicrystalline, quasi-liquid and liquid states coexisted at the same temperature. Both layers appeared to be solid at the lowest temperature studied. For $T>265 \mathrm{~K}$ the upper layer became increasingly liquid-like with increasing temperature, whereas the lower layer of water molecules remained generally solidlike up to $T=325 \mathrm{~K}$. The lower layer consisted of five- and six-membered rings centered on the iodine ring with dipole moments preferentially oriented parallel to the substrate and nearly zero dipole moment projection perpendicular to the substrate. This indicates that at least in the second adsorbed layer ice formation above about $265 \mathrm{~K}$ is inhibited by the free surface entropy. For the AgI prism face, the first water monolayer is even less structured than on the basal AgI face. Possible remedies for this difficult situation for ice formation on AgI are not lacking. Some preliminary simulations for two water layers on a model basal face ledge indicate that the ledge is marginally better at promoting ice structure in the upper layer.

Shevkunov (2005) simulated the nucleation of water vapors on the 001 face of $\beta \mathrm{AgI}$ (basal face) by the Monte Carlo method in a humid atmosphere at $273 \mathrm{~K}$. They found that already below the liquid water saturation pressure, the crystal surface is covered with a water monolayer. The molecules in this layer are arranged above the iodine ions, between the silver ions, and are interconnected with hydrogen bonds forming the regular structure with hexagonal symmetry. Deposition of a second water layer needed supersaturation, indicating that the condensation of water vapor into a macroscopic phase is prevented by a high free-energy barrier. A point defect in the form of an extra ion on the surface virtually did not distort the hexagonal structure of the first water monolayer.

In a follow-up study, Shevkunov (2008) performed Monte Carlo simulations of water vapor nucleation on the basal plane (001) surface of a $\beta$ AgI crystal with and without defects. They concluded that the matching minimizes disorder in layer structure and therefore enhances stability of the layers, promoting layer-by-layer growth. The most stable orientations of molecules in monolayers adjacent to the substrate are parallel and perpendicular to it. The formation of each layer involved overcoming a nucleation barrier. The film thickness is an increasing function of pressure. As the saturation pressure is exceeded, the vapor explosively condensed into a dense macroscopic phase via layer-by-layer growth. The barriers that suppress the nucleation of successive monolayers can be eliminated by substrate surface defects. However, a point defect did not significantly change the macroscopic behavior of the condensed phase. Extended defects, such as cracks or fractures, should be much more effective in this respect.

Zielke et al. (2015) used molecular dynamics simulations at a supercooling of $20 \mathrm{~K}$ to investigate ice nucleation on surfaces representing faces of $\beta \mathrm{AgI}$ and $\gamma \mathrm{AgI}$. These simulations showed that a good lattice match with ice is insufficient to predict the ice nucleation ability of an AgI surface. When the basal planes of hexagonal ice are compared, only the 001 
face terminated by $\mathrm{Ag}^{+}$ions nucleates ice and not the iodideterminated $00 \overline{1}$ face, although both faces have identical lattice matches with ice. This was ascribed to the configuration that the surface imposes on the water molecules. On the silver exposed surface, the oxygen atoms of the water molecules take a chair conformation, which resembles the chair conformation present in hexagonal and cubic ice. In contrast, for the iodide exposed surface the hexagonal rings form a more coplanar structure that does not match any surface of ice, and no ice nucleation occurred on this face. Moreover, cubic and hexagonal ice was observed to nucleate on both the $\beta$ form and the $\gamma$ form of AgI. On the silver- and iodide-terminated prism face, no ice could be observed. The authors speculate that a templating mechanism may be active in cases of close lattice match so that particular AgI surfaces impose a structure on the adjacent water layer that closely resembles a layer that exists in bulk ice (hexagonal or cubic). Ice nucleates at these surfaces and grows almost layer-by-layer into the bulk. They emphasize that this mechanism does not rule out defects being important for ice nucleation by silver iodide, but indicates that defects are not necessary in order to explain why silver iodide particles can be highly effective ice nuclei.

Performing simulations at supercooling of $10 \mathrm{~K}$, Fraux and Doye (2014) also came to the conclusion that ice nucleates on the silver-terminated basal surfaces of $\beta \mathrm{AgI}$ but not on the iodide-terminated ones. The ice formation occurred via a two-step mechanism. A hexagonal ice-like bilayer of strongly adsorbed water molecules immediately formed on the surface. After a certain lag time, a nucleation event occurred and ice started to grow on the top of this layer. Although a somewhat similar adsorbed layer formed on the $\mathrm{I}^{-}$-terminated surface, this layer was unable to initiate ice growth. Similarly, although water molecules strongly adsorbed on the prism faces, these layers are less obviously ice-like and were unable to act as templates for ice growth on the timescales of the simulations.

\section{B5 Contact angle of water on silver iodide}

The contact angle of polycrystalline AgI depends on the silver concentration of the wetting liquid. Billett et al. (1976) measured the contact angle of an air bubble against thin films of silver iodide in an electrolyte solution using the captive bubble technique. The films consisted of a two-dimensional array of tightly packed, polydisperse micro- and nanocrystals of mainly trigonal and hexagonal shape. The size of the bubble was orders of magnitudes larger than the size of the crystals. Highest contact angle values were obtained for silver concentrations $\mathrm{pAg}=4-7$, namely $70-73^{\circ}$ for the advancing liquid meniscus, $20-24^{\circ}$ for the receding liquid meniscus and $45-50^{\circ}$ for the intermediate advancing angle. Lowest values were obtained for $\mathrm{pAg}=1$, with $16^{\circ}$ for the advancing, $9^{\circ}$ for the receding and $30^{\circ}$ for the intermediate advancing angle, and $\mathrm{pAg}=13$, with $16^{\circ}$ for the advancing, $9^{\circ}$ for the receding and $9^{\circ}$ for the intermediate advancing angle. The maximum value was realized close to the PZC with $\mathrm{pAg}=5.4 \pm 0.2$. This can be expected if one assumes that the spreading of water will be enhanced when the surface charge tends to orient the water molecules into a position that is energetically more favorable than the orientation of the bulk at the charged interface would be (Bijsterbosch and Lyklema, 1978).

\section{B6 Dissolution of AgI particles in the CLINCH and IMCA-ZINC chambers}

An approximate dissolution rate of particles can be calculated by the Noyes-Whitney equation (Dokoumetzidis and Macheras, 2006):

$\frac{\mathrm{d} M}{\mathrm{~d} t}=-\left(\frac{D}{h}\right) A\left(C_{\mathrm{s}}-C_{t}\right)$,

where $\mathrm{d} M / \mathrm{d} t$ describes the mass loss per time, $D$ is the diffusion coefficient, $A$ is the surface area of the particle(s), $C_{\mathrm{s}}$ and $C_{t}$ are the saturation concentration and the concentration at time $t$, respectively, and $h$ is a thin static liquid layer at the solid surface under steady-state conditions.

Diffusion coefficients of ions in aqueous solutions increase with increasing temperature. For $\mathrm{Ag}^{+}$the diffusion coefficient is $D=8.5 \times 10^{-6} \mathrm{~cm}^{2} \mathrm{~s}^{-1}$ at $273 \mathrm{~K}$ and $16.6 \times$ $10^{-6} \mathrm{~cm}^{2} \mathrm{~s}^{-1}$ at $298 \mathrm{~K}$. The diffusion coefficient is slightly larger for $\mathrm{I}^{-}$with $10.3 \times 10^{-6} \mathrm{~cm}^{2} \mathrm{~s}^{-1}$ at $273 \mathrm{~K}$ and $20.0 \times$ $10^{-6} \mathrm{~cm}^{2} \mathrm{~s}^{-1}$ at $298 \mathrm{~K}$ (Li and Gregory, 1974). For the liquid layer $h$, a value equal to the particle radius is often assumed (Sheng et al., 2008). Silver iodide is a sparingly soluble salt with a solubility product of around $10^{-16}$ at $298 \mathrm{~K}$ (Hiemstra, 2012; Lyklema, 1966). The solubility decreases with decreasing temperature and reaches a value $<10^{-17}$ at $273 \mathrm{~K}$ (Lyklema, 1966). For an estimated saturation concentration of AgI in water of $C_{\mathrm{s}}=7.4 \times 10^{-10} \mathrm{~g} \mathrm{~cm}^{-3}$ at $T<273 \mathrm{~K}$ and assuming $C_{t}=0$, we obtain $\mathrm{d} M / \mathrm{d} t=9 \times 10^{-19} \mathrm{~g} \mathrm{~s}^{-1}$ for a $200 \mathrm{~nm}$ particle and $\mathrm{d} M / \mathrm{d} t=9 \times 10^{-20} \mathrm{~g} \mathrm{~s}^{-1}$ for a $20 \mathrm{~nm}$ particle. To reach saturation concentration in an $80 \mu \mathrm{m}$ droplet at $273 \mathrm{~K}, 2 \times 10^{-16} \mathrm{~g} \mathrm{AgI}$ need to dissolve. With 2 or $4 \mathrm{~s}$ residence times in the chamber, it can be assumed that the particle is constantly dissolving while in the chamber. The situation is different in the IMCA-ZINC chamber. The activation of the AgI particles to cloud droplets occurs at $T>273 \mathrm{~K}$ and the droplets grow only to $20 \mu \mathrm{m}$. Therefore, only $3 \times 10^{-18} \mathrm{~g} \mathrm{AgI}$ need to dissolve to reach saturation concentration in the droplet at $273 \mathrm{~K}$. At $298 \mathrm{~K}$, dissolution occurs at a higher rate of $\mathrm{d} M / \mathrm{d} t=6 \times 10^{-18} \mathrm{~g} \mathrm{~s}^{-1}$ for a $200 \mathrm{~nm}$ particle and at $\mathrm{d} M / \mathrm{d} t=6 \times 10^{-19} \mathrm{~g} \mathrm{~s}^{-1}$ for a $20 \mathrm{~nm}$ particle. Residence time in the IMCA part is approximately $15 \mathrm{~s}$. Therefore, there seems to be enough time to reach saturation within the IMCA section. The droplets may even become supersaturated with respect to AgI within the ZINC section because dissolution occurred at $T>273 \mathrm{~K}$ and the saturation concentration is higher at this temperature than at the temperature in the ice nucleation section. 
Edited by: D. Knopf

Reviewed by: two anonymous referees

\section{References}

Aguerd, M., Clausse, D., and Babin, L.: Heterogeneous nucleation of ice by $\mathrm{AgI}$ in water droplets dispersed within emulsions, CryoLett., 3, 164-171, 1982.

Anderson, B. J. and Hallett, J.: Supersaturation and time dependence of ice nucleation from the vapor on single crystal substrates, J. Atmos. Sci., 33, 822-832, doi:10.1175/15200469(1976)033<0822:SATDOI>2.0.CO;2, 1976.

Barchet W. R. and Corrin, M. L.: Water vapor adsorption by pure silver iodide above ice saturation, J. Phys. Chem., 76, 22802285, doi:10.1021/j100660a018, 1972.

Barnes, G. T.: Phase transitions in water sorbed on ice forming nuclei, Z. Angew. Math. Phys., 14, 510-518, 1963.

Barnes, G. T. and Sänger, R.: An investigation into the mechanism of ice crystal nucleation by proton spin resonance spectroscopy, Z. Angew. Math. Phys., 12, 159-164, doi:10.1007/BF01601015, 1961.

Bassett, D. R., Boucher, E. A., and Zettlemoyer, A. C.: Adsorption studies on ice-nucleating substrates. Hydrophobed silicas and silver iodide, J. Colloid Interf. Sci., 34, 436-446, doi:10.1016/0021-9797(70)90203-1, 1970.

Berry, C. R.: Structure and optical absorption of AgI microcrystals, Phys. Rev., 161, 848-851, doi:10.1103/PhysRev.161.848, 1967.

Bijsterbosch, B. H. and Lyklema, J.: Interfacial electrochemistry of silver iodide, Adv. Colloid Interfac., 9, 147-251, doi:10.1016/0001-8686(87)80005-2, 1978.

Billett, D. F., Hough, D. B., and Ottewill, R. H.: Studies on the contact angle of the charged silver iodide-solution-vapour interface, J. Electroanal. Chem., 74, 107-120, doi:10.1016/S00220728(76)80217-3, 1976.

Breed, D., Rasmussen, R., Weeks, C., Boe, B., and Deshler, T.: Evaluating winter orographic cloud seeding: Design of the Wyoming Weather Modification Pilot Project (WWMPP), J. Appl. Meteorol. Climatol., 53, 282-299, doi:10.1175/JAMC-D13-0128.1, 2014.

Bruintjes, R. T.: A review of cloud seeding experiments to enhance precipitation and some new prospects, B. Am. Meteorol. Soc., 80, 805-820, doi:10.1175/15200477(1999)080<0805:AROCSE> 2.0.CO;2, 1999.

Bryant, G. W., Hallett, J., and Mason B. J.: The epitaxial growth of ice on single-crystalline substrates, J. Phys. Chem. Solids, 12, 189-195, 1959

Budke, C. and Koop, T.: BINARY: an optical freezing array for assessing temperature and time dependence of heterogeneous ice nucleation, Atmos. Meas. Tech., 8, 689-703, doi:10.5194/amt-8689-2015, 2015.

Burley, G.: Polymorphism of silver iodide, Am. Mineral., 48, 12661276, 1963.

Cantrell, W. and Robinson, C.: Heterogeneous freezing of ammonium sulfate and sodium chloride solutions by long chain alcohols, Geophys. Res. Lett., 33, L07802, doi:10.1029/2005GL024945, 2006.

Cava, R. J. and Rietman, E. A.: Ionic conductivity of $\beta$-AgI, Phys. Rev. B, 30, 6896-6902, doi:10.1103/PhysRevB.30.6896, 1984.
Chen, B. and Xiao H.: Silver iodide seeding impact on the microphysics and dynamics of convective clouds in the high plains, Atmos. Res., 96, 186-207, doi:10.1016/j.atmosres.2009.04.001, 2010.

Conrad, P., Ewing, G. E., Karlinsey, R. L., and Sadtchenko, V.: Ice nucleation on $\mathrm{BaF}_{2}(111)$, J. Chem. Phys., 122, 064709, doi:10.1063/1.1844393, 2005

Corrin, M. L. and Nelson, J. A.: Energetics of the adsorption of water vapor on "pure" silver iodide, J. Phys. Chem., 72, 643645, doi:10.1021/j100848a043, 1968.

Corrin, M. L., Edwards, H. W., and Nelson, J. A.: The surface chemistry of condensation nuclei: II. The preparation of silver iodide free of hygroscopic impurities and its interaction with water vapor, J. Atmos. Sci., 21, 565-567, doi:10.1175/15200469(1964)021<0565:TSCOCN>2.0.CO;2, 1964.

Davis, B. L., Johnson, L. R., and Moeng, F. J.: An explanation for the unusual nucleating ability of aerosols produced from the AgI-NH $4 \mathrm{I}$-acetone system, J. Appl. Meteorol. 14, 891-896, doi:10.1175/1520-0450(1975)014<0891:AEFTUN> 2.0.CO;2, 1975.

DeMott, P. J.: Quantitative descriptions of ice formation mechanisms of silver iodide-type aerosols, Atmos. Res., 38, 63-99, doi:10.1016/0169-8095(94)00088-U, 1995.

DeMott, P. J., Finnegan, W. G., and Grant, L. O.: An application of chemical kinetic theory and methodology to characterize the ice nucleating properties of aerosols used for weather modification, J. Clim. Appl. Meteorol., 22, 1190-1203, doi:10.1175/15200450(1983)022<1190:AAOCKT>2.0.CO;2, 1983.

Djikaev, Y. S. and Ruckenstein E.: Thermodynamics of heterogeneous crystal nucleation in contact and immersion modes, J. Phys. Chem. A, 112, 11677-11687, doi:10.1021/jp803155f, 2008.

Dokoumetzidis, A. and Macheras, P.: A century of dissolution research: From Noyes and Whitney to the biopharmaceutics classification system, Int. J. Pharm., 321, 1-11, doi:10.1016/j.ijpharm.2006.07.011, 2006.

Durant, A. J. and Shaw, R. A.: Evaporation freezing by contact nucleation inside-out, Geophys. Res. Lett., 32, L20814, doi:10.1029/2005GL024175, 2005.

Edwards, G. R. and Evans, L. F.: Ice nucleation by silver iodide: I. Freezing vs sublimation, J. Meteorol., 17, 627-634, doi:10.1175/1520-0469(1960)017<0627:INBSII>2.0.CO;2, 1960.

Edwards, G. R. and Evans, L. F.: Effect of surface charge on ice nucleation by silver iodide, T. Faraday Soc., 58, 1649-1655, doi:10.1039/tf9625801649, 1962.

Edwards, G. R. and Evans, L. F.: Ice nucleation by silver iodide: III. The nature of the nucleating site, J. Atmos. Sci., 25, 249-256, doi:10.1175/1520-0469(1968)025<0249:INBSII>2.0.CO;2, 1968.

Edwards, G. R., Evans, L. F., and La Mer, V. K.: Ice nucleation by monodisperse silver iodide particles, J. Colloid Sci., 17, 749758, doi:10.1016/0095-8522(62)90049-1, 1962.

Fitzner, M., Sosso, G. C., Cox, S. J., and Michaelides, A.: The many faces of heterogeneous ice nucleation: Interplay between surface morphology and hydrophobicity, J. Am. Chem. Soc., 137, 13658-13669, doi:10.1021/jacs.5b08748, 2015.

Fletcher, N. H.: Entropy effect in ice crystal nucleation, J. Chem. Phys. 30, 1476-1482, doi:10.1063/1.1730221, 1959. 
Fornea, A. P., Brooks, S. D., Dooley, J. B., and Saha, A.: Heterogeneous freezing of ice on atmospheric aerosols containing ash, soot, and soil, J. Geophys. Res., 114, D13201, doi:10.1029/2009JD011958, 2009.

Fraux, G. and Doye, J. P. K.: Note: Heterogeneous ice nucleation on silver-iodide-like surfaces, J. Chem. Phys., 141, 216101, doi:10.1063/1.4902382, 2014.

Fukuta, N. and Paik, Y.: Water adsorption and ice nucleation on silver iodide surfaces, J. Appl. Phys., 44, 1092-1100, doi:10.1063/1.1662311, 1973.

Garstang, M., Bruintjes, R., Serafin, R., Orville, H., Boe, B., Cotton, W., and Warburton, J.: Weather modification - Finding common ground, B. Am. Meteorol. Soc., 86, 647-655, doi:10.1175/BAMS-86-5-647, 2005.

Gokhale, N. R. and Goold, J.: Droplet freezing by surface nucleation, J. Appl. Meteorol., 7, 870-874, 1968.

Gokhale, N. R. and Lewinter, O.: Microcinematographic studies of contact nucleation, J. Appl. Meteorol. 10, 469-473, 1971.

Govindarajan A. G. and Lindow S. E.: Size of bacterial ice-nucleation sites measured in situ by radiation inactivation analysis, P. Natl. Acad. Sci. USA, 85, 1334-1338, doi:10.1073/pnas.85.5.1334, 1988.

Guo, Y.-G., Lee, J.-S., and Maier, J.: Preparation and characterization of AgI nanoparticles with controlled size, morphology and crystal structure, Solid State Ionics, 177, 2467-2471, doi:10.1016/j.ssi.2006.02.043, 2006.

Gurganus, C. W., Charnawskas, J. C., Kostinski, A. B., and Shaw, R. A.: Nucleation at the contact line observed on nanotextured surfaces, Phys. Rev. Lett., 113, 235701, doi:10.1103/PhysRevLett.113.235701, 2014.

Hall, P. G. and Tompkins, F. C.: Adsorption of water vapour on insoluble metal halides, T. Faraday Soc., 58, 1734-1745, doi:10.1039/tf9625801734, 1962.

Head, R. B.: Steroids as ice nucleators, Nature, 191, 1058-1059, doi:10.1038/1911058a0, 1961.

Hiemstra, T.: Variable charge and electrical double layer of mineral-water interfaces: silver halides versus metal (hydr)oxides, Langmuir, 28, 15614-15623, doi:10.1021/1a303584a, 2012.

Hoffer, T. E.: A laboratory investigation of droplet freezing, J. Meteorol., 18, 766-778, doi:10.1175/15200469(1961)018<0766:ALIODF>2.0.CO;2, 1961.

Kajava, A. V. and Lindow, S. E.: A model of the three-dimensional structure of ice nucleation proteins, J. Mol. Biol., 232, 709-717, doi:10.1006/jmbi.1993.1424, 1993.

Kallay, N., Preočanin, T., Šupljika, F., Lützenkirchen, J., and Lovković, M.: Influence of interfacial water layer on surface properties of silver halides: effect of $\mathrm{pH}$ on the isoelectric point, J. Colloid Interf. Sci., 375, 167-171, doi:10.1016/j.jcis.2012.02.041, 2012.

Klimeš, J., Bowler, D. R., and Michaelides, A.: Understanding the role of ions and water molecules in the $\mathrm{NaCl}$ dissolution process, J. Chem. Phys., 139, 234702, doi:10.1063/1.4840675, 2013.

Knopf, D. A. and Forrester, S.: Freezing of water and aqueous $\mathrm{NaCl}$ droplets coated by organic monolayers as a function of surfactant properties and water activity, J. Phys. Chem. A, 115, 5579-5591, doi:10.1021/jp2014644, 2011.
Ladino Moreno, L. A., Stetzer, O., and Lohmann, U.: Contact freezing: a review of experimental studies, Atmos. Chem. Phys., 13, 9745-9769, doi:10.5194/acp-13-9745-2013, 2013.

Langer G., Cooper, G., Nagamoto, C. T., and Rosinski, J.: Ice nucleation mechanisms of submicron monodispersed silver iodide, 1,5-dihydroxynaphtalene and phloroglucinol aerosol particles, J. Appl. Meteorol., 17, 1039-1048, doi:10.1175/15200450(1978)017<1039:INMOSM>2.0.CO;2, 1978.

Li, Y. H. and Gregory, S.: Diffusion of ions in sea water and in deepsea sediments, Geochim. Cosmochim. Ac., 38, 708-714, 1974.

Lüönd, F., Stetzer, O., Welti, A., and Lohmann, U.: Experimental study on the ice nucleation ability of size-selected kaolinite particles in the immersion mode, J. Geophys. Res., 115, D14201, doi:10.1029/2009JD012959, 2010.

Lyklema, J: Electrical double layer on silver iodide - Influence of temperature and application to sol stability, Discuss. Faraday Soc., 42, 81-90, 1966.

Lyklema, J. and Golub, T.: Electrical double layer on silver iodide and overcharging in the presence of hydrolyzable cations, Croat. Chem. Acta, 80, 303-311, 2007.

Majewski, J., Margulis, L., Weissbuch, I., Popovitz-Biro, R., Arad, T., Talmon, Y., Lahav, M., and Leiserowitz, L.: Electron microscopy studies of amphiphilic self-assemblies on vitreous ice, Adv. Mater., 7, 26-35, doi:10.1002/adma.19950070104, 1995.

Manson, J. E.: X-ray diffraction study of silver iodide aerosols, J. Appl. Phys., 26, 423-425, doi:10.1063/1.1722011, 1955.

Marcolli, C.: Deposition nucleation viewed as homogeneous or immersion freezing in pores and cavities, Atmos. Chem. Phys., 14, 2071-2104, doi:10.5194/acp-14-2071-2014, 2014.

Mason, B. J. and van den Heuvel: The properties and behavior of some artificial ice nuclei, Proc. Phys. Soc., 74, 744-755, doi:10.1088/0370-1328/74/6/312, 1959.

Morgan, B. J. and Madden, P. A.: Effects of lattice polarity on interfacial space charges and defect disorder in ionically conducting AgI heterostructures, Phys. Rev. Lett., 107, 206102, doi:10.1103/PhysRevLett.107.206102, 2011.

Murray, B. J., O’Sullivan, D., Atkinson, J. D., and Webb, M. E.: Ice nucleation by particles immersed in supercooled cloud droplets, Chem. Soc. Rev., 41, 6519-6554, doi:10.1039/c2cs35200a, 2012.

Nagare, B., Marcolli, C., Stetzer, O., and Lohmann, U.: Comparison of measured and calculated collision efficiencies at low temperatures, Atmos. Chem. Phys., 15, 13759-13776, doi:10.5194/acp15-13759-2015, 2015.

Nagare, B., Marcolli, C., Welti, A., Stetzer, O., and Lohmann, U.: Comparing contact and immersion freezing from continuous flow diffusion chambers, Atmos. Chem. Phys., 16, 8899-8914, doi:10.5194/acp-16-8899-2016, 2016.

Nicolet, M., Stetzer, O., Lüönd, F., Möhler, O., and Lohmann, U.: Single ice crystal measurements during nucleation experiments with the depolarization detector IODE, Atmos. Chem. Phys., 10, 313-325, doi:10.5194/acp-10-313-2010, 2010.

Palanisamy, M., Thangaraj, K., Gobinathan, R., and Ramasamy, P.: $\mathrm{X}$-ray diffraction and ice nucleation studies of $\mathrm{AgI}-\mathrm{AgCl}$ solid solutions, J. Cryst. Growth, 79, 1005-1009, doi:10.1016/00220248(86)90587-7, 1986a.

Palanisamy, M., Thangaraj, K., Gobinathan, R., and Ramasamy, P.: Effect of particle size on the ice nucleating ability of 
AgI-AgBr-CuI system, Cryst. Res. Technol., 21, 853-857, doi:10.1002/crat.2170210709, 1986b.

Pokharel, B., Geerts, B., Jing, X., Friedrich, K., Aikins, J., Breed, D., Rasmussen, R., and Huggins, A.: The impact of ground-based glaciogenic seeding on clouds and precipitation over mountains: A multi-sensor case study of shallow precipitating orographic cumuli, Atmos. Res., 147, 162-182, doi:10.1016/j.atmosres.2014.05.014, 2014.

Popovitz-Biro, R., Wang, J. L., Majewski, J., Shavit, E., Leiserowitz, L., and Lahav, M.: Induced freezing of supercooled water into ice by self-assembled crystalline monolayers of amphiphilic alcohols at the air-water interface, J. Am. Chem. Soc., 116, 1179-1191, doi:10.1021/ja00083a003, 1994.

Sadtchenko, V., Ewing, G. E., Nutt, D. R., and Stone, A. J.: Instability of ice films, Langmuir, 18, 4632-4636, doi:10.1021/la0255370, 2002.

Sax, R. I. and Goldsmith, P.: Nucleation of water drops by Brownian contact with AgI and other aerosols, Q. J. Roy. Meteor. Soc., 98, 60-72, doi:10.1002/qj.49709841506, 1972.

Schaller, R. C. and Fukuta, N.: Ice nucleation by aerosol particles: Experimental studies using a wedge-shaped ice thermal diffusion chamber, J. Atmos. Sci., 36, 1788-1802, doi:10.1175/15200469(1979)036<1788:INBAPE>2.0.CO;2, 1979.

Seinfeld, J. H. and Pandis, S. N.: Atmospheric Chemistry and Physics: From Air Pollution to Climate Change: John Wiley \& Sons, Inc., 2006.

Shaw, R. A., Durant, A. J., and Mi, Y.: Heterogeneous surface crystallization observed in undercooled water, J. Phys. Chem. B, 109, 9865-9868, doi:10.1021/jp0506336, 2005.

Sheng J. J., Sirois, P. J., Dressman, J. B., and Amidon, G. L.: Particle diffusional layer thickness in a USP dissolution apparatus II: A combined function of particle size and paddle speed, J. Pharm. Sci., 97, 4815-4829, doi:10.1002/jps.21345, 2008.

Shevkunov, S. V.: Computer simulation of the initial stage of water vapor nucleation on a silver iodide crystal surface: 1 . Microstructure, Colloid J., 67, 548-560, doi:10.1007/s10595-005-0124-2, 2005.

Shevkunov, S. V.: Stimulation of vapor nucleation on perfect and imperfect hexagonal lattice surfaces, J. Exp. Theor. Phys., 107, 965-983, doi:10.1134/S1063776108120078, 2008.

Sidebottom, E. W., House, W. A., and Jaycock, M. J.: Investigation on the surface structure of precipitated silver iodide samples by Krypton adsorption, J. Chem. Soc. Faraday T. I, 72, 2709-2721, doi:10.1039/f19767202709, 1976.

Silverman, B. A.: A critical assessment of glaciogenic seeding of convective clouds for rainfall enhancement, B. Am. Meteorol. Soc., 82, 903-923, doi:10.1175/15200477(2001)082<0903:ACAOGS>2.3.CO;2, 2001.

Sjogren, S., Gysel, M.,Weingartner, E., Baltensperger, U., Cubison, M. J., Coe, H., Zardini, A. A., Marcolli, C., Krieger, U. K., and Peter, T.: Hygroscopic growth and water uptake kinetics of twophase aerosol particles consisting of ammonium sulfate, adipic and humic acid mixtures, J. Aerosol Sci., 38, 157-171, 2007.

Taylor, J. H. and Hale, B. N.: Monte Carlo simulations of waterice layers on a model silver iodide substrate: A comparison with bulk ice systems, Phys. Rev. B, 47, 9732-9741, doi:10.1103/PhysRevB.47.9732, 1993.
Tcheurekdjian, N., Zettlemoyer, A. C., and Chessick, J. J.: The adsorption of water vapor onto silver iodide, J. Phys. Chem., 68, 773-777, doi:10.1021/j100786a010, 1964.

Tomaev, V. V., Tver'yanovich, Yu. S., and Bal'makov, M. D.: Mechanical modification of $\beta$-AgI nanocrystals, Crystallogr. Rep., 57, 948-954, doi:10.1134/S106377451207022X, 2012.

Vali, G., DeMott, P. J., Möhler, O., and Whale, T. F.: Technical Note: A proposal for ice nucleation terminology, Atmos. Chem. Phys., 15, 10263-10270, doi:10.5194/acp-15-10263-2015, 2015.

Vonnegut, B.: The nucleation of ice formation by silver iodide, J. Appl. Phys. 18, 593-595, doi:10.1063/1.1697813, 1947.

Vonnegut, B. and Baldwin, M.: Repeated nucleation of a supercooled water sample that contains silver iodide particles, J. Clim. Appl. Meteorol., 23, 486-490, doi:10.1175/15200450(1984)023<0486:RNOASW>2.0.CO;2, 1984.

Vonnegut B. and Chessin H.: Ice nucleation by coprecipitated silver iodide and silver bromide, Science, 174, 945-946, doi:10.1126/science.174.4012.945, 1971.

Waychunas, G. A.: Disrupting dissolving ions at surfaces with fluid flow, Science, 344, 1094-1095, doi:10.1126/science.1254906, 2014.

Welti, A., Lüönd, F., Kanji, Z. A., Stetzer, O., and Lohmann, U.: Time dependence of immersion freezing: an experimental study on size selected kaolinite particles, Atmos. Chem. Phys., 12, 9893-9907, doi:10.5194/acp-12-9893-2012, 2012.

Yankofsky, S. A., Levin Z., Bertold T., and Sandlerman, N.: Some basic characteristics of bacterial freezing nuclei, J. Appl. Meteorol., 20, 1013-1019, doi:10.1175/15200450(1981)020<1013:SBCOBF>2.0.CO;2, 1981.

Zettlemoyer, A. C., Tcheurekdjian, N., and Chessick, J. J.: Surface properties of silver iodide, Nature, 192, 653, doi:10.1038/192653a0, 1961.

Zettlemoyer, A. C., Tcheurekdjian, N., and Hosler, C. L.: Ice nucleation by hydrophobic substrates, Z. Angew. Math. Phys., 14, 496-502, doi:10.1007/BF01601255, 1963.

Zielke, S. A., Bertram, A. K., and Patey, G. N.: A molecular mechanism of ice nucleation on model AgI surfaces, J. Phys. Chem. B, 119, 9049-9055, doi:10.1021/jp508601s, 2015.

Zimmermann, F., Ebert, M., Worringen, A., Schütz, L., and Weinbruch, S.: Environmental scanning electron microscopy (ESEM) as a new technique to determine the ice nucleation capability of individual atmospheric aerosol particles, Atmos. Environ., 41, 8219-8227, doi:10.1016/j.atmosenv.2007.06.023, 2007.

Zobrist, B., Koop, T., Luo, B. P., Marcolli, C., and Peter, T.: Heterogeneous ice nucleation rate coefficient of water droplets coated by a nonadecanol monolayer, J. Phys. Chem. C, 111, 2149-2155, doi:10.1021/jp066080w, 2007.

Zobrist, B., Marcolli, C., Peter, T., and Koop T.: Heterogeneous ice nucleation in aqueous solutions: the role of water activity, $\mathrm{J}$. Phys. Chem. A, 112, 3965-3975, doi:10.1021/jp7112208, 2008. 